\title{
mHealth Application Areas and Technology Combinations*
}

\section{A Comparison of Literature from High and Low/Middle Income Countries}

Haitham Abaza; Michael Marschollek

Peter L. Reichertz Institute for Medical Informatics, Hannover Medical School, Hannover, Germany

\section{Keywords}

mHealth, low and middle income countries, mobile health solutions

\section{Summary}

Background: With the continuous and enormous spread of mobile technologies, mHealth has evolved as a new subfield of eHealth. While eHealth is broadly focused on information and communication technologies, mHealth seeks to explore more into mobile devices and wireless communication. Since mobile phone penetration has exceeded other infrastructure in low and middle-income countries (LMICS), mHealth is seen as a promising component to provide pervasive and patient-centered care.

Objectives: The aim of our research work for this paper is to examine the mHealth literature to identify application areas, target diseases, and mHealth service and technology types that are most appropriate for LMICS.

Methods: Based on the 2011 WHO mHealth report, a combination of search terms, all including the word "mHealth", was identified. A literature review was conducted by searching the PubMed and IEEE Xplore databases. Articles were included if they were published

Correspondence to:

Haitham Abaza

Peter L. Reichertz Institute for Medical Informatics Hannover Medical School

Carl-Neuberg-Str. 1

30625 Hannover

Germany

E-mail: haitham.abaza@plri.de

Supplementary material published on our website https://doi.org/10.3414/ME17-05-0003 in English, covered an mHealth solution/ intervention, involved the use of a mobile communication device, and included a pilot evaluation study. Articles were excluded if they did not provide sufficient detail on the solution covered or did not focus on clinical efficacy/effectiveness. Cross-referencing was also performed on included articles.

Results: 842 articles were retrieved and analyzed, 255 of which met the inclusion criteria. North America had the highest number of applications ( $n=74)$ followed by Europe $(n=50)$, Asia $(n=44)$, Africa $(n=25)$, and Australia $(n=9)$. The Middle East $(n=5)$ and South America $(n=3)$ had the least number of studies. The majority of solutions addressed diabetes ( $n=51)$, obesity $(n=25)$, CVDs $(n=24)$, HIV ( $n=18)$, mental health $(n=16)$, health behaviors $(n=16)$, and maternal and child's health $(M C H)(n=11)$. Fewer solutions addressed asthma $(n=7)$, cancer $(n=5)$, family health planning $(n=5), T B(n=3)$, malaria $(n=2)$, chronic obtrusive pulmonary disease (COPD) $(n=2)$, vision care $(n=2)$, and dermatology $(n=2)$. Other solutions targeted stroke, dental health, hepatitis vaccination, cold and flu, ED prescribed antibiotics, iodine deficien$c y$, and liver transplantation ( $n=1$ each). The

Methods Inf Med 2017; 56(Open): e105-e122 https://doi.org/10.3414/ME17-05-0003 received: February 23, 2017 accepted: May 25, 2017 published: August 8, 2017 remainder of solutions ( $n=14$ ) did not focus on a certain disease. Most applications fell in the areas of health monitoring and surveillance $(n=93)$ and health promotion and raising awareness $(n=88)$. Fewer solutions addressed the areas of communication and reporting $(n=11)$, data collection $(n=6)$, telemedicine $(n=5)$, emergency medical care $(n=3)$, point of care support $(n=2)$, and decision support $(n=2)$. The majority of solutions used SMS messaging $(n=94)$ or mobile apps $(n=71)$. Fewer used IVR/phone calls $(n=8)$, mobile website/email $(n=5)$, videoconferencing $(n=2)$, MMS $(n=2)$, or video $(n=1)$ or voice messages $(n=1)$. Studies were mostly $\mathrm{RCTs}$, with the majority suffering from small sample sizes and short study durations. Problems addressed by solutions included travel distance for reporting, self-management and disease monitoring, and treatment/medication adherence.

Conclusions: SMS and app solutions are the most common forms of mHealth applications. SMS solutions are prevalent in both high and LMICs while app solutions are mostly used in high income countries. Common application areas include health promotion and raising awareness using SMS and health monitoring and surveillance using mobile apps. Remaining application areas are rarely addressed. Diabetes is the most commonly targeted medical condition, yet remains deficient in LMICs. 


\section{Introduction}

Healthcare delivery in low and middle income countries (LMICs) suffers from a myriad of problems. The World Health Organization (WHO) estimated a deficit of 4.3 million healthcare workers in 57 developing countries [1], leading to understaffed hospitals, lack of patient access to care, and a huge patient-physician communication gap, especially in rural areas. Community healthcare workers (CHWs) play a vital role in bridging this gap, yet have to travel long distances and lose enormous amounts of time [1]. Geographical barriers also prevent the elderly from reaching hospitals to seek medical care, while shortage of hospital beds prohibits proper monitoring of those with chronic illness [2]. Moreover, missed appointments remain a very crucial issue, as patients may have to wait as long as a month to be seen by an appropriate physician. Drug and treatment adherence rates also remain low for prevalent diseases such as human immunodeficiency virus (HIV) and tuberculosis (TB), mainly due to lack of awareness [3]. Likewise, lack of knowledge on reproductive health makes LMICs account for $99 \%$ of maternal deaths worldwide, representing one of the widest health gaps between the developed and the developing world [4].

The Earth Institute at Columbia University estimated over 3.5 billion mobile phone subscribers in a 3.3 billion population in late 2007 [5]. The International Telecommunication Union (ITU) estimated nearly six billion mobile subscribers in 2011 , rendering $87 \%$ mobile penetration rate globally and $79 \%$ in the developing world $[4,6]$. Moreover, according to the British operator Vodafone, the developing world had 2.2 billion mobile phones in 2010 as opposed to 11 million hospital beds [2]. The United Nations (UN) goal of 50\% wireless coverage by 2015 was also surpassed, with the mobile signal covering $90 \%$ of the world's population in 2009 and 143 countries offering third generation (3G) services in 2010 [3].

With this continuous and enormous spread of mobile technologies, mHealth has evolved as a new subfield of eHealth [7]. While eHealth is broadly focused on information and communication technol- ogies, mHealth seeks to explore more into mobile devices and wireless communication [8]. To this point, no standardized definition for mHealth has been established, but the WHO defines it as the use of mobile phones, patient monitoring devices, personal digital assistants (PDAs), and other wireless technologies to support medical and public health practice $[7,9]$. It was estimated that $50 \%$ of individuals in remote areas of the world would have mobile phones as of 2012 [10], and 500 million people would have access to smartphone mHealth applications by 2015 [3]. Accordingly, mHealth is expected to carry all the promises of eHealth [10,11].

Using technologies such as short message service (SMS) and PDA/smartphone apps, mHealth has great potential to minimize health problems and improve healthcare delivery, particularly in LMICs. SMS programs have been conducted to educate patients and raise awareness, provide adherence and appointment reminders, facilitate data reporting and communication, and assist in data collection and creation of medical records [12]. Further, text messaging has also improved maternal and child's health $(\mathrm{MCH})$ by guiding women through the various stages of pregnancy $[4,13]$. Additionally, PDAs have been used to provide home-based counseling and collect basic health information necessary for detecting HIV and TB [14]. Smartphone apps have encouraged self-management of chronic diseases such as diabetes, eliminating unnecessary hospitalizations and emergency room visits, thus reducing healthcare costs $[15,16,17]$. They have also supported remote and home-based monitoring, particularly for the elderly, providing physicians with real-time health data and empowering patients to become more involved in their treatment process $[2,17]$. Lately, behavioral change programs have recognized the potential of SMS and smartphone apps to promote physical activity, weight management, and smoking cessation $[18$, $19,20,21]$.

Due to this wide range of applications, the field of mHealth is seen as a promising component to provide pervasive and patient-centered care and its potential has been recognized by both the UN and the WHO $[7,9]$. There is no consensus in the literature on how to classify mHealth application areas [8], yet the WHO and the mHealth Alliance have identified the following: treatment compliance, health promotion and disease prevention, awareness raising over health issues, health monitoring, disease surveillance, communication, data collection, mobile telemedicine, point of care and decision support, and emergency medical response [7, 22]. In 2011, the WHO marked health call centers and decision support systems to be the most and least commonly used initiatives among its Member States respectively. Gaps were also identified in using mHealth for surveillance and raising awareness. The most significant barrier to mHealth implementation was knowledge and information, among others such as conflicting health system priorities, lack of supporting policy, and legal issues in European countries as opposed to infrastructure in African countries [7]. The WHO also identified six types of mHealth technologies, of which the most documented feature was SMS messaging. Remaining technologies included PDAs and smartphones, patient monitoring devices, mobile telemedicine/telecare devices, MP3 players, and mobile computing [23].

This paper aims to review mHealth applications worldwide and provide comparisons between high income countries (HICs) and LMICs, seeking to identify a target disease, an application area, and an mHealth technology type that are most appropriate for LMICs. The remainder of the paper is organized as follows: The "methods" section describes our search process including sources, selection criteria, and extracted data. The "results" section presents the findings of our literature review and illustrates popular application area/ technology combinations. The "discussion" section compares our findings to those of the WHO report and discusses the observations we made during our literature analysis. The "conclusions" section concludes the paper, providing information on promising application areas and suggesting future research. 


\section{Methods}

\subsection{Data Sources}

Upon reviewing the $2011 \mathrm{WHO}$ mHealth report which described initiatives from Member States [7], and the 2010 mHealth Alliance white paper focused on barriers and gaps in LMICs [22], appropriate search terms were identified. On August $3^{\text {rd }}$ 2015, we searched the PubMed and IEEE Xplore databases using the queries presented in - Table 1. However, as the MeSH term for "mHealth" had become "telemedicine" by 2014, we used quotation marks to switch off automatic $\mathrm{MeSH}$ replacement on PubMed and avoid retrieval of a myriad of unrelated articles. On IEEE Xplore, we used the command search with metadata only. Cross-referencing was also performed on selected articles.

\subsection{Selection Criteria}

Articles were included if they (1) focused explicitly on one or more mHealth solutions/interventions, covering details about the problem the intervention attempted to overcome, the country and disease addressed, and the solution name if applicable. Solutions also had to (2) involve the use of a mobile communication device such as mobile phones, tablets, or PDAs; and provide infrastructure information regarding the technologies used. Infrastructure information included details on necessary means of data communication such as internet $(\mathrm{WiFi})$, mobile broadband signal coverage (3G, GPRS, etc.) or Bluetooth technology; in addition to other types of technologies involved such as servers, modems, personal monitoring devices or special software for data analysis and transmission. Solutions that involved the use of other types of mobile devices, yet transmitted data over the mobile network were also included. Finally, articles had to (3) involve a clinical study/trial (pilot evaluation) that tested the mHealth intervention on a sample of participants and evaluated its impact on health outcomes. Only English articles were included and no date restrictions were applied.

Articles were excluded if they (1) did not meet the inclusion criteria. For instance, articles that did not involve a sol-
Table 1 Search queries.

\begin{tabular}{|c|c|}
\hline PubMed & IEEE Xplore \\
\hline $\begin{array}{l}\text { (((((((" mhealth" [All Fields] AND "solutions"[All Fields]) OR } \\
\text { ("mhealth"[All Fields] AND "initiatives"[All Fields])) OR } \\
\text { ("mhealth"[All Fields] AND "applications"[All Fields])) OR } \\
\text { ("mhealth"[All Fields] AND "infrastructure"[All Fields])) OR } \\
\text { ("mhealth"[All Fields] AND "projects"[All Fields])) OR } \\
\text { ("mhealth"[All Fields] AND "interventions"[All Fields])) OR } \\
\text { ("mhealth"[All Fields] AND "implementation"[All Fields])) OR } \\
\text { ("mhealth"[All Fields] AND "evaluation"[All Fields])) OR } \\
\text { ("mhealth"[All Fields] AND "barriers"[All Fields]) }\end{array}$ & $\begin{array}{l}\text { ((((((((mhealth AND solutions) OR } \\
\text { (mhealth AND initiatives)) OR } \\
\text { (mhealth AND applications)) OR } \\
\text { (mhealth AND infrastructure)) OR } \\
\text { (mhealth AND projects)) OR } \\
\text { (mhealth AND interventions)) OR } \\
\text { (mhealth AND implementation)) OR } \\
\text { (mhealth AND evaluation)) OR } \\
\text { (mhealth AND barriers) }\end{array}$ \\
\hline
\end{tabular}

ution/intervention and instead assessed readiness for mHealth or surveyed mobile phone ownership or attitudes/interest towards mHealth applications were excluded. Moreover, solutions that did not involve the use of a mobile communication device and instead only used a personal monitoring device, transmitted data via a landline phone, or applied the intervention through a website were excluded. Articles were also excluded if they focused on the design or development of the mHealth solution or described a commercial application without involving a clinical study. Additionally, we excluded articles that (2) did not provide sufficient detail on the solution covered. Solution details included basic study data such as the solution name if any, the study location, and the disease addressed; study design data such as sample size, duration, interventions and mHealth technology used, and primary/secondary outcomes; and study results. Accordingly, incomplete studies and study protocols were excluded. Finally, we excluded studies that (3) did not involve any focus on the medical impact/benefits of the solution or its clinical efficacy/effectiveness (CE). Accordingly, studies that only addressed feasibility, usability, acceptability, validation, technology performance, user satisfaction and engagement, or cost-effectiveness were excluded. Moreover, studies that combined the use of mHealth technologies with other types of technologies where the mHealth impact could not be extracted were also excluded.

\subsection{Data Extraction}

Retrieved articles were initially screened for potential inclusion by applying the se- lection criteria to their titles and abstracts and eliminating those that were clearly not in line. The full text of remaining articles was then reviewed and only ones that complied with the above criteria were included. Cross-referencing was also performed on their reference lists and further articles meeting the selection criteria were identified and included. Initial grouping was applied to articles describing the same studies or addressing the same mHealth solutions (some solutions were tested in several trials with different study designs). Studies were primarily classified based on their mHealth application areas, then further classifications were derived based on diseases addressed, study countries, study types, mHealth technology types, and users of focus. The following details were also extracted from each study: the name of the solution, methods and interventions applied, infrastructure technologies used, sample size and study duration, problem addressed, assessment instruments used, primary and secondary outcomes, study results, user opinions, and study limitations. A summary of these study details is provided in $>$ Online Appendix A.

\section{Results}

\subsection{Summary of Findings}

The literature search yielded 680 articles that were assessed against our selection criteria. By reviewing titles and abstracts, 331 articles were excluded mainly as they did not describe an mHealth solution/intervention $(\mathrm{n}=149)$, or they did not involve a clinical study ( $\mathrm{n}=148)$. After full text review of remaining articles $(n=349), 256$ further exclusions were made mostly since 


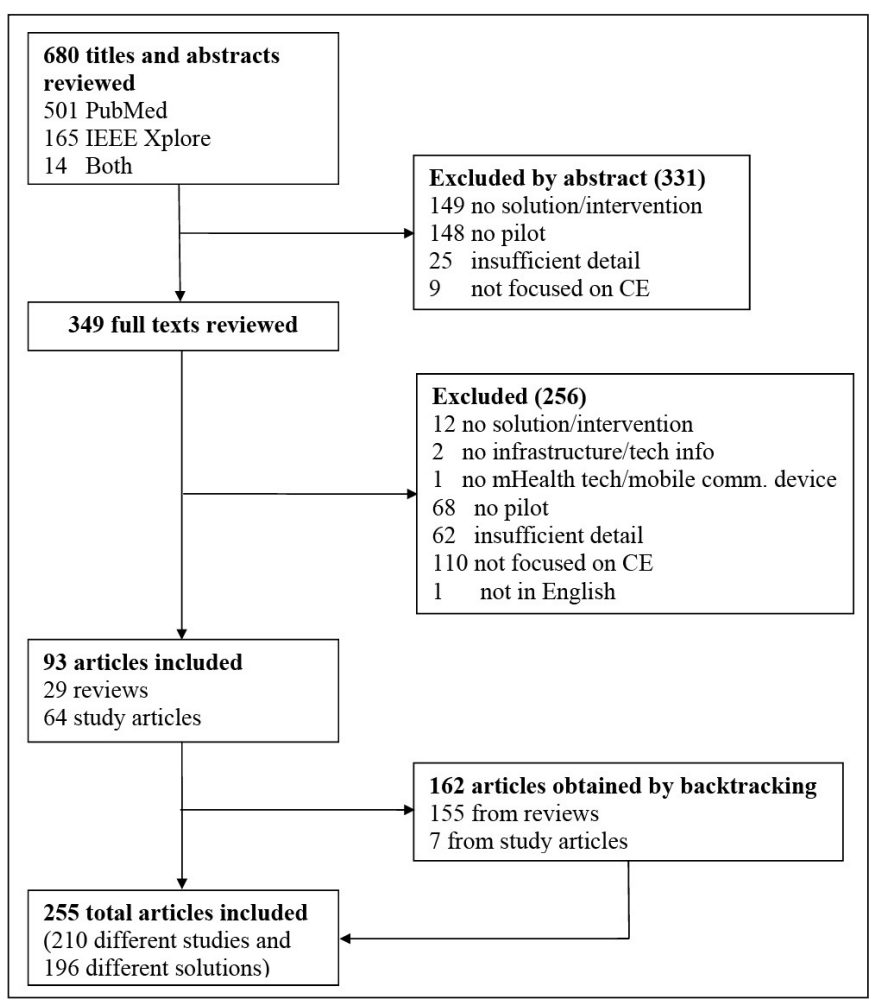

Figure 1

Search and review process. they did not focus on the medical impact/ benefits of the solution or its clinical efficacy/effectiveness $(n=110)$, they did not involve a clinical study $(n=68)$, or they did not provide sufficient detail on the study covered $(n=62)$. Remaining 93 articles were included, 29 of which were review papers while 64 addressed individual studies. Cross-referencing was performed identifying 162 further articles for inclusion. A total of 255 articles were finally included in this review, representing 210 different studies and 196 different solutions. The study selection flow is shown in Figure 1 .

Articles were published between the years 2001 and 2015, with the majority of publications appearing as of 2008. The year 2012 marked the highest number of publications, which explains the difference between the findings of this review and those of the WHO report. Areas receiving the least focus in the report such as surveillance and raising awareness seemed to receive more attention as of 2012. Literature reviews seemed to considerably increase as of late 2013, with 23 out of 29 reviews published between 2013 and 2015, thus culminating in a large number of publications included in this review by cross-referencing.

\subsection{Study Characteristics}

Based on the WHO's classification of mHealth categories, eight application areas were identified in this review. Most studies fell in the area of health monitoring and surveillance $(n=93)$, followed by health promotion and raising awareness $(n=88)$, communication and reporting $(n=11)$, data collection $(n=6)$, telemedicine $(n=5)$, emergency medical care $(n=3)$, point of care support $(\mathrm{n}=2)$, and decision support $(n=2)$. The majority of studies took place in North America $(n=74)$, mainly in the United States (USA) $(\mathrm{n}=64)$ and Canada $(n=9)$. European studies $(n=50)$ were mostly located in the United Kingdom $(n=11)$, Spain $(n=7)$, the Netherlands $(n=5)$ and Finland $(n=5)$. Studies conducted in Asia $(n=44)$ primarily took place in South Korea $(n=12)$, followed by India $(n=7)$ and China $(n=6)$. The majority of African studies $(n=25)$ were conducted in Kenya $(n=6)$, Uganda $(n=5)$, and South Africa $(n=4)$. Australian studies $(n=9)$ took place in Australia $(n=7)$ and New Zealand $(n=2)$. The least number of studies appeared to be in the Middle East $(n=5)$ and South America $(n=3)$, comprising studies in Iran $(n=3)$, Turkey $(n=1)$, Israel $(n=1)$, Brazil $(n=2)$, and Argentina $(n=1)$ respectively. Overall, 61 studies were located in LMICs as opposed to 149 in HICs.

Randomized controlled trials (RCTs) $(n=132)$ were the most common study design, followed by pre-post studies $(n=43)$, pilots $(n=20)$, controlled $(n=13)$ and randomized $(n=2)$ studies. SMS messages $(n=94)$ were the most widely used mHealth technology type, followed by smartphone/ PDA apps $(n=71)$, a combination of SMS

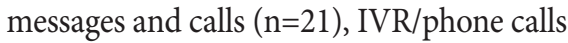
$(\mathrm{n}=8)$, and mobile website/email $(\mathrm{n}=5) . \mathrm{A}$ few studies used text messages other than SMS ( $n=3)$, videoconferencing $(n=2)$, combined SMS with MMS ( $\mathrm{n}=2)$ or SMS with an app $(n=2)$, or sent video $(n=1)$ or voice messages $(n=1)$. Study durations ranged from one week to 26 months with sample sizes of three to 39800 participants. The most commonly addressed medical conditions were diabetes $(n=51)$, obesity $(n=25)$, CVDs $(n=24)$, HIV $(n=18)$, mental health $(n=16)$, health behaviors $(n=16)$, and $\mathrm{MCH}$ $(n=11)$. Fewer studies addressed asthma $(n=7)$, cancer $(n=5)$, family health planning $(n=5)$, TB $(n=3)$, malaria $(n=2)$, chronic obtrusive pulmonary disease (COPD) $(n=2)$, vision care $(n=2)$, and dermatology $(n=2)$. Single studies targeted stroke, dental health, hepatitis vaccination, cold and flu, emergency department (ED) prescribed antibiotics, iodine deficiency, and liver transplantation. The remaining 14 studies were generally directed towards any health condition and did not focus on a particular disorder. Three studies addressed both diabetes and hypertension together and were assigned to either diabetes or CVD studies based on their primary outcomes. Finally, 180 studies focused primarily on patients or individuals as the users or main recipients of the mHealth intervention, 19 studies were mainly designed for healthcare providers, and 11 studies combined their focus between patients and medical staff.

\subsection{Intended Benefits}

Health promotion and raising awareness studies intended to improve patients' access to care, appointment attendance, medication and treatment adherence, and in- 
crease their motivation to sustain healthy behaviors. They also intended to improve patients' and providers' knowledge, support under-skilled CHWs, and overcome time and distance barriers patients usually experience with traditional educational programs. Health monitoring and surveillance studies mainly targeted adherence to treatment, medications, self-monitoring, and health behaviors. Communication and reporting studies intended to overcome communication barriers faced by healthcare providers such as travel distance and time, and promote timely exchange of health information $[1,4,6,24,25,26,27]$. They also addressed gaps in patient-physician communication arising from patients' inability to promptly reach a physician and difficulty understanding their physician's medical advice [28, 29]. Data collection applications aimed to minimize errors associated with traditional lengthy paper-based data collection methods $[30,31]$, and the time required to train poorly educated CHWs [32]. Telemedicine solutions intended to deliver care to remote locations by overcoming time constraints, transportation difficulties, travel distance, and costs [2, 33, 34, 35]. Emergency medical care applications planned to improve transportation times to hospitals, minimize unnecessary transportations to tertiary care, and eliminate medical errors associated with patient handoffs, especially in emergency situations $[36,37,38]$. Point of care support studies intended to support nurses and residents at the bedside, thus minimizing medication administration errors and facilitating stroke evaluations and presentations [39, 40]. Decision support applications intended to overcome the shortage of skilled healthcare workers [41].

\subsection{Common Application Area/ Technology Combinations}

\subsubsection{Health Monitoring and Surveillance + Apps (HM+app)}

App solutions comprised 39 out of 93 studies that fell under the area of health monitoring and surveillance. They incorporated monitoring of vital measurements via automatic or manual entry to a smartphone or PDA, or monitoring of health behaviors. Remaining studies used phone calls, a combination of calls and SMS, multimedia messages, SMS, mobile internet, or a combination of app and SMS. Apps were either intended for self-monitoring, capturing readings from external devices such as glucometers, pedometers, or blood pressure (BP) monitors; or health behaviors, allowing users to monitor their medications, dietary intake, and exercise levels.

Most apps in this category transmitted entered data to a server where it was available for healthcare providers to accordingly provide feedback via phone calls, text messages, or visiting the patients. For instance, diabetes apps such as WellDoc [15, 42], Bant [43], Patient's Mobile Unit (PMU) [44], Diabetes Assistant (DiAs) [45], Glucose Buddy [46], t+ Diabetes [47], DIABTel [48], Diab-Memory [49], WellMate [50], and t+ Medical [51] allowed patients to enter their glucometer readings into a smartphone or a PDA, and sent them to the healthcare provider for follow-up and personalized feedback. HbAlc was measured in seven studies, only one of which did not manage to achieve improvement [50]. Other studies indicated a reduced rate of emergency department visits and hospitalizations [15], an increase in the average daily frequency of blood glucose measurement [43], an increase in patient confidence [44], and a decrease in the duration of hypoglycemic events [45].

Likewise, CVD apps, such as Healthanywhere [52] and others [53, 54, 55, 56, 57, 58, 59], captured ECG data, heart rate, blood pressure, and weight measurements from portable devices, and alerted cardiologists when readings fell out of range. Most apps resulted in significant improvements in systolic blood pressure [55, 57, 58], allcause mortality and heart failure hospitalizations [54], heart failure prognosis [56], and patients' exercise capacity (walking distance) [59]. In Taiwan, COPD patients followed the tempo of a music app while walking to record their respiratory symptoms and send them to their physicians [60], whereas in the UK, the $t+$ Asthma app was used to record and transmit symptoms, medication use, and peak flow to healthcare providers; and trigger contact by an asthma nurse in case of emergency [61]. The COPD app significantly improved pa- tients' walking distance and breathlessness, whereas the asthma app had no significant effects on asthma control or self-efficacy.

Health behavioral apps incorporated monitoring dietary intake, physical activity, medication adherence, and alcohol use. Obesity apps, such as the Meal Replacement Program (MRP) app [62] and My Meal Mate (MMM) [63], allowed users to record their weights, meals, and physical activity; and generated motivational text messages to enhance self-efficacy and reflect on progress. Others, such as $\mathrm{mPOD}$ $[64,65]$ and DietMatePro [66, 67], allowed recording dietary intake and physical activity, and accordingly provided individualized counseling via twitter or phone calls [68]. The Livestrong app [69] allowed wireless tracking of dietary intake and physical activity, and provided real-time feedback on the number of calories consumed, prompted participants to self-monitor at regular intervals, and provided a time stamp for each record. The Wellness Diary app [18] allowed daily entries of meals and drinks, weight, step count, exercise sessions, daily feelings, and health events; and sent data to researchers every week. Only the Livestrong app measured and improved adherence to self-monitoring of diet and physical activity goals, while all remaining apps focused on weight loss.

Medication adherence apps included the mAMS app [70] that read data from medication blisters, recorded time stamps and number of pills taken, and sent data to a server for analysis via mobile internet. They also included the Pill Phone app [71] which reminded patients to take their pills by automatically displaying the picture and name of the medication, and requesting patients to tap either the "taken," "not taken," or "snooze" button to stop the reminder. All responses were then stored in a server database for future retrieval by authorized users. Both apps caused significant or nearly significant improvements in medication adherence. In Portugal, alcohol dependent individuals improved their frontal lobe function and cognitive abilities by using a game app that allowed health providers to assess their brain function [72], while in USA the A-CHESS app significantly reduced the frequency of risky drinking by supporting alcoholics and pro- 
viding ways for them to remain in contact with their counselors after discharge [73]. The FOCUS app [74] prompted schizophrenic patients to complete three assessments per day, and accordingly provided tailored interventions to facilitate symptom management, mood regulation, medication adherence, social functioning, and improved sleep. Of the 39 studies in this category, only one was conducted in a LMIC.

\subsubsection{Health Monitoring and Surveillance + SMS (HM+SMS)}

Health monitoring SMS solutions marked 35 out of 93 studies. The category addressed health behaviors, where medication reminders and electronic monitoring were most commonly incorporated. Moreover, self-monitoring solutions used websites rather than a mobile app to submit selfmonitored data, and patients accordingly received SMS feedback. For instance, studies such as the HIV Alert System (HIVAS) [75], ARemind [76], SIMPill [77], CareSpeak mobile Health manager [78, 79], and a Kenyan HIV study [80] sent SMS medication reminders to participants, and recorded pill counts with time and date stamps via an electronic medication event monitoring system (MEMS). The My Medication Reminder Text Messaging Program [81] in USA sent SMS medication reminders to chronic disease patients, and monitored their adherence to oral medication via their electronic pharmacy claims and the number of prescription fills/refills. WelTel Kenya1 [82] measured antiretroviral therapy (ART) adherence by sending SMS messages to participants inquiring about their status, reminding them about the availability of phone support, and calling those failing to respond. With the exception of SIMPill, all studies reported higher adherence to pill counts, oral medication, and ART respectively.

A study in USA improved CD4 counts and viral load by sending HIV patients $1-3$ text messages daily on medication regimen, and requiring them to answer weekly adherence questions via two-way messaging [83]. The TextTB [84] study in Argentina sent SMS reminders to participants if they did not text in after taking their medi- cation, while a study in Canada sent Vitamin $\mathrm{C}$ reminders to participants followed by a correction SMS about its benefits to those failing to respond [85], thus improving self-reported adherence. In USA, the MediM adherence system study [86] reduced the tacrolimus level SD by sending SMS alerts to pediatric liver transplant recipients to take their immunosuppressors, and a message to the caregivers of those who did not respond so that they could monitor their compliance online. The SMS-DMCare [87] program sent diabetics personalized medication, foot care, and appointment reminders; and scheduled further messages based on their responses. The study decreased missed medication doses per week and significantly improved patients' self-efficacy. Other behaviors were addressed by two studies in the Netherlands that required obese children to send weekly self-monitoring data on exercise, eating behavior, and emotional well-being via SMS to a web server, and accordingly generated and sent tailored feedback messages $[88,89,90]$. Reductions in body mass index, however, did not reach statistical significance.

Self-monitoring supported by SMS featured mainly diabetes, CVDs, asthma, and mental health studies. The CARDS study in USA [91], in addition to multiple studies in South Korea [92, 93, 94, 95, 96, 97, 98, 99], required diabetic participants to enter their blood glucose readings into a website, and accordingly provided them with SMS feedback. Likewise, the Gluconet [100], Diabetes Phone [101], NICHE [102], DMS [103], and a South Korean study [104] asked diabetics to upload their blood glucose data onto a server via a specially designed glucometer device, mobile broadband, a modem, or a telephone line; and sent them SMS advice and recommendations accordingly. All studies measured and often improved HbAlc levels; commonly indicating significant reductions from baseline, yet rarely reporting significant differences between study groups at endpoint. Similar CVD studies in Spain $[105,106]$ and Russia [107] also asked participants to submit their blood pressure, heart rate, and weight monitoring data via a WAP session or an IT system, and accordingly sent them SMS recommen- dations or scheduled them for clinic visits if necessary. Both studies reported improved blood pressure levels at follow-up.

Asthmatic patients in Croatia were instructed to submit their peak expiratory flow (PEF) results daily via SMS, and accordingly received weekly SMS instructions from an asthma specialist [108], whereas those in the eCare study in Singapore received SMS monitoring messages, sent according to a structured workflow, to improve asthma control and reduce hospital admissions [109]. PEF variability showed significant differences between study groups but no change in admission rates was observed. Patients suffering from depression in USA were asked to monitor their daily mood, submit a mood score of 1-9 via SMS, and report positive thoughts, pleasant activities, social interactions, and healthy activities [110]. Improvement in the likelihood to attend therapy sessions was indicated. In the ITAREPS study, schizophrenic patients were instructed to submit a weekly SMS questionnaire, and if any early warning signals were identified, the physician was notified by an email and accordingly the patient was contacted by phone to adjust the dose of antisychotic medications $[111,112,113]$. The study reported significant reductions in hospitalizations and number of hospital days. Only five studies (out of 35) in this category took place in LMICs.

\subsubsection{Health Promotion and Raising Awareness + SMS (HP+SMS)}

The majority of studies ( $n=56$ out of 88 ) that fell under health promotion and raising awareness were SMS solutions, while remaining studies used phone calls, a combination of calls and SMS, multimedia messages, apps, or mobile internet. SMS messages delivered information to patients, acted as reminders to improve appointment and medication adherence, contained educational content to promote self-care, and took motivational formats to encourage healthy lifestyle behaviors. Educational, motivational, and reminder messages sometimes requested a response from patients providing answers to knowledge questions, confirming that preset behavioral goals had been met, or confirming tak- 
ing their medication dose. Messages were also sometimes tailored to patients' ages, stages of illness, compliance with behavioral goals, or stage of smoking cessation. An automatic scheduling and sending service or software was often incorporated, but sometimes messages were also manually initiated.

In the CommCare study [114], lab results were delivered to participants via SMS messages that requested patients with abnormal results to return to care. SMS reminders improved appointment attendance in various countries (Brazil, China, UK, India, Spain) by reminding patients to attend their clinic or follow-up appointments $[115,116]$, their therapy sessions [117], their dental visits [118], or their hepatitis vaccination appointments [119]. The APAS study [120] reduced the number of missed antenatal care (ANC) visits by sending SMS reminders to CHWs advising them to visit their assigned households, and remind mothers and children of their clinic appointments. SMS reminders also increased the practice of breast self-examinations [121], on-time attendance of ANC and immunization visits [122], and reduced the number of days between scheduled appointments and actual attendance for contraceptive injection [123]. The HTAAlert study [124] and a Malaysian study [125], which sent SMS messages to remind patients to take their antihypertensive drugs and cardiac medications, reported increased hypertension control and medication adherence respectively. Likewise, medication reminders were used to prompt patients to take their malaria pills [126], schizophrenia [127], asthma [128], or diabetes medications [129]. Compliance with malaria chemoprophylaxis did not increase above baseline, but all other studies reported increased adherence. Reminders promoting healthy dietary behaviors [130], asthma management [131], and malaria case-management [132] were also sometimes sent in Korea, China, and Kenya; resulting in improved weight, forced expiratory volume (FEV1), and correct malaria case-management respectively.

Educational messages were sent to mothers to improve their prenatal knowledge $[133,134]$, encourage them to take care of their children's dental health [135], or increase their attendance of antenatal visits [136]. They were also used to provide sexual education [137], measure HIV knowledge [12, 138], and encourage the uptake of HIV counseling and testing [139]. SMS queries with educational feedback were used to get patients discharged from the ED to pick up their antibiotic prescriptions [140], yet no differences in adherence were observed. The TExT-MED [141, 142] and the CareSmarts [143] studies sent educational/motivational messages to patients to promote diabetes self-care, and observed progress in selfmanagement behaviors as well as reductions in HbA1c levels. Another study in Iran sent diabetes educational messages on exercise, diet, diabetic medication, and self-monitoring of blood glucose levels; and reported significant improvement in glycemic control and self-efficacy [144]. Educational messages also increased knowledge levels as they were sent to educate patients about their epilepsy [145] or provide them with information about iodine deficiency [146], improved the quality of life of asthmatic patients [147], and optimized the patient-physician relationship for psoriasis patients [148].

Behavioral change messages were used in several studies to monitor nutritional and physical activity goals $[149,150]$ and encourage weight loss [151, 152, 153, 154]. They were also used to promote brisk walking [155] as well as physical activity for cardiac rehabilitation [156], resulting in reduced weight and improved self-efficacy respectively. Motivational messages were used to promote medication adherence among HIV, mental illness, and asthmatic patients [157, 158, 159]; aspirin adherence among CVD patients [160]; and encourage family health planning via the use of contraception [161, 162]. Tailored messages and personalized goal-specific prompts improved $\mathrm{HbAlc}$ and self-efficacy as they were used in the Sweet Talk study to promote diabetes healthy behaviors [163], while lifestyle modification messages reduced the incidence rate of diabetes when sent to pre-diabetics in China to decrease their risk of developing diabetes [164]. Messages aiming to decrease alcohol consumption were addressed by the TOPHAT-2 study [165], while those targeting tobacco use were included in the Stop My Smoking USA [166], TXT-2-Quit [167], and SMS-Turkey [168] studies. Smokers were sent SMS messages, tailored to their smoking cessation stages, to support them quit or abstain from smoking and resist their craving episodes. Significant differences in continuous abstinence between study groups were, however, not observed. It is worth noting that 22 out of 56 studies in this category were located in LMICs.

\subsubsection{Health Promotion and Raising Awareness + Apps (HP+app)}

App solutions comprised 13 of the 88 health promotion and raising awareness studies. Apps were installed on a smartphone, a tablet, or a PDA to educate or train patients and promote self-monitoring and healthy lifestyle behaviors. In Thailand, village health volunteers (VHVs) used educational material provided on a tablet to conduct presentations during their household visits, train mothers to address their child's health, and promote behavioral change [169]. The study reported increased vaccination coverage and knowledge levels. Likewise, CHWs in Bangladesh used the mPower app to guide their interviews with women and identify those with abnormal clinical breast examinations [170]. The app led to increased efficiency and efficacy of interviews and higher adherence to attending clinic visits. In Finland, working people used the Oiva app to learn skills related to mental wellness and receive exercises to relieve their daily life stress [171], resulting in improved stress rating and life satisfaction scores. Diabetes diary apps were used in Norway and Italy to allow self-monitoring of blood glucose levels and promote healthy eating and physical activity [172, 173, 174]. Reductions in HbA1c levels were reported, yet without statistical significance. Further, a home monitoring kit improved clinical and blood panel measures as it was provided to patients in Canada to record their weight, blood pressure, and blood glucose levels; and promote healthy aging [175].

Behavioral change apps encouraged fruit and vegetable (FV) intake via daily morning alarm reminders [176], and promoted eating breakfast via positive and 
negative responses to submitted breakfast photos [177]. Both studies reported improved FV and breakfast consumption respectively. The UOIFit fitness application in Canada decreased the body mass index as it measured and counted exercises performed via a tracking software [178], while the Chick clique app in USA increased step count as it encouraged walking via entering and comparing pedometer steps among its group of users [179]. In Korea, significant reductions in body composition measures were observed after using the SmartDiet app, which provided personalized nutrition information, calculated the proper calorie and exercise level, and provided game-style guidance on how to control nutritional intake and exercise [180]. In the Netherlands, the MORE Energy app was used to support healthy behaviors and reduce sleep problems among airline pilots [181], leading to reduced fatigue and improved sleep quality and snacking behavior. Only two of the 13 studies in this category were conducted in LMICs.

\subsubsection{Other Application Areas and Technology Combinations}

Studies in the area of communication and reporting were mostly conducted in LMICs ( $\mathrm{n}=8$ out of 11 studies). Though a few studies used apps, the majority used SMS, phone calls, or a combination of both. Users of mhealth solutions in this category were mostly healthcare providers. CHWs used SMS or calls to report danger signs, patient adherence, or request information; and received medical advice, appointment reminders, and emergency assistance from district physicians [1, 4, 6, 24]. In Project Mwana [25], the turnaround time for result notification dropped significantly as health facilities used SMS to indicate to the lab that the blood samples had been packed and sent, while the lab sent them the results also by SMS when they were ready. In the World Vision Project [182], communication flows and knowledge seeking behavior improved as midwives received mobile phone calls to facilitate communication with gynecologists, and reduce maternal and infant mortality. Cancer follow-up appointment attendance increased in Nigeria as patients were given their oncologists' phone numbers, and were asked to call anytime to seek medical advice [28]. App solutions were used to provide information exchange between healthcare providers $[183,26]$, deliver video and image instructions to patients [29], and support CHWs in recording household data and managing referrals [27].

In the data collection area, all studies were app solutions, with four out of six located in LMICs and led by healthcare providers. VHVs in Thailand increased data quality and completeness by using the mobile camera application to capture images of the mothers' logbooks and record immunization data [30]. In the CommCare study [32], CHWs' training time considerably dropped as they used a mobile app to calculate CVD risk and limit the errors that resulted from paper charts. CHWs in Kenya used an Android-based app to collect patients' data during household visits [14], and midwives in Senegal utilized their mobile phones to collect maternal health data during their survey interviews with postpartum women [31]. Both studies reported increased number of household visits per day and reduced time to collect maternal data respectively. Data collection apps were also used by patients to gather information about mood, activity, psychotic symptoms, and drinking episodes $[184,185]$.

Telemedicine solutions were all used by healthcare providers and delivered via videoconferencing, SMS, and apps. Two out of five studies were located in LMICs. In USA, Skype video sessions were held with patients in their home environment to help them cope with cancer pain [33], indicating significantly decreased pain severity, physical symptoms, psychological distress, and pain catastrophizing. Videoconferencing was also used in Sri Lanka to allow physicians in a general hospital deliver care to patients in a peripheral setting [2], significantly reducing travel costs, distance, and time. Likewise, the TeleMDID app in USA allowed communication between health staff at near site clinics with specialized staff (dermatologists) at far site clinics [34], increasing the efficiency of appointments and improving the teledermatology workflow. Remote centers in Cameroon significantly reduced systolic blood press- ure levels by sending patients' data to the telemedicine center everyday via SMS, and receiving immediate real-time feedback via phone calls in urgent cases [35]. As a replacement to the PACS image viewer, physicians in the ResMD study used an app on a smartphone and a tablet to access patient images faster, particularly when away from the hospital [186], thus reducing the timeto-first-image and increasing diagnostic confidence.

Emergency medical care studies were all app solutions intended for ambulances, paramedics, and ED nurses; and one out of three studies was located in a LMIC. Tablets were used in ambulances in China and Japan to allow efficient sharing of information between the emergency personnel and the medical staff at the hospital, and allow for preparation of necessary interventions at the hospital while patients were still in the pre-hospital phase [36, 37]. Both studies reported reduced transportation times. A smartphone app in USA was also used to allow paramedics to record audio/ video, capture images, and collect basic patient information, then send them to the ED staff at the hospital via the mobile broadband network [38]. The study indicated improved communication between hospital and pre-hospital transport and a higher percentage of incidents sent by emergency personnel with essential patient information.

Point of care support studies comprised two app solutions intended to support nurses and residents at the bedside. A tablet system was used in Italy to monitor the administration of chemotherapy medications in the hospital, and verify that the right drugs were being administered to the right patients in the right sequence [39]. The study, however, found no significant differences in chemotherapy administration before and after the system was introduced. A smartphone app was also used in USA to assist healthcare providers in gathering stroke patients' data necessary to determine their candidacy for t-PA, and assist residents in optimizing the completeness and efficiency of their stroke evaluations and case presentations to staff neurologists [40]. Notable and slight reductions were observed in door-to-needle time and neurologists' data abstraction time respect- 
ively. None of the two studies took place in a LMIC.

Decision support was addressed by two studies, one of which took place in a LMIC. Both studies were app solutions intended for use by healthcare providers. The Vision Care app allowed for patient data entry via drop-down lists to minimize errors, and provided decision support to field workers, irrespective of their skills, during patient counseling at checkup camps [41]. The app reduced data input and referral decision times and increased the number of referrals per day. The other study included a diabetes app that reduced $\mathrm{HbAlc}$ levels via a patient-coaching system and provider clinical decision support [187]. No differences were observed, however, between study groups in diabetes symptoms or blood pressure and lipid levels.

\subsection{Analysis of Results}

According to the WHO [188], non-communicable diseases (NCDs) cause 38 million deaths each year, nearly $75 \%$ (28 million) of which occur in LMICs. CVDs are responsible for most NCD deaths, namely 17.5 million people annually, followed by cancers (8.2 million), respiratory diseases (4 million), and diabetes (1.5 million). The four main NCDs combined account for $82 \%$ of all NCD deaths. In addition to study distributions, these numbers necessitate the examination of NCD studies appearing in our review among HICs and LMICs.

In terms of the overall amount of studies conducted, the review established that HICs are vastly surpassing LMICs; with the number of studies in the former exceeding double that in the latter. Of 210 studies, 149 were based in HICs as opposed to 61 in LMICs. SMS messages and smartphone/ PDA apps are the most popular mHealth technology types. They were almost equally used in developed countries, comprising 64 SMS and 61 app studies. In LMICs, however, the use of SMS messages highly exceeded that of smartphone/PDA apps, with 30 studies incorporating SMS vs. only 10 incorporating apps. Although this could indicate a deficiency in using apps in LMICs, it also shows higher suitability of SMS messages in the developing world,

Table 2 Study distributions among high and low and middle income countries.

\begin{tabular}{|c|c|c|c|c|}
\hline \multirow{2}{*}{$\begin{array}{l}\text { Application area/technology type/disease } \\
\text { combinations }\end{array}$} & \multicolumn{2}{|l|}{ LMICs } & \multicolumn{2}{|l|}{ HICs } \\
\hline & Studies & Countries & Studies & Countries \\
\hline Health promotion and raising awareness $(n=88)$ & 33 & 16 & 55 & 16 \\
\hline$H P+S M S(n=56)$ & 22 & 12 & 34 & 12 \\
\hline HP+SMS focused on main 4 NCDs $(n=17)$ & 6 & 4 & 11 & 6 \\
\hline$H P+a p p(n=13)$ & 2 & 2 & 11 & 9 \\
\hline HP+app focused on main 4 NCDs $(n=4)$ & 1 & 1 & 3 & 4 \\
\hline Health monitoring and surveillance $(n=93)$ & 12 & 10 & 81 & 21 \\
\hline$H M+S M S(n=35)$ & 5 & 4 & 30 & 11 \\
\hline HM+SMS focused on main 4 NCDs $(n=20)$ & 1 & 1 & 19 & 8 \\
\hline HM+app (n=39) & 1 & 1 & 38 & 13 \\
\hline HM+app focused on main 4 NCDs $(n=28)$ & 1 & 1 & 27 & 12 \\
\hline Communication and reporting $(n=11)$ & 8 & 7 & 3 & 2 \\
\hline Data collection $(n=6)$ & 4 & 4 & 2 & 1 \\
\hline Telemedicine $(n=5)$ & 2 & 2 & 3 & 1 \\
\hline Emergency medical care $(n=3)$ & 1 & 1 & 2 & 2 \\
\hline Point of care support $(n=2)$ & 0 & 0 & 2 & 2 \\
\hline Decision support $(n=2)$ & 1 & 1 & 1 & 1 \\
\hline \multicolumn{5}{|l|}{ Diabetes Studies } \\
\hline Health promotion and raising awareness $(n=14)$ & 4 & 4 & 10 & 6 \\
\hline$H P+S M S(n=8)$ & 3 & 3 & 5 & 2 \\
\hline HP+app $(n=3)$ & 0 & 0 & 3 & 4 \\
\hline Health monitoring and surveillance $(n=36)$ & 4 & 4 & 32 & 12 \\
\hline$H M+S M S(n=14)$ & 0 & 0 & 14 & 5 \\
\hline$H M+a p p(n=16)$ & 1 & 1 & 15 & 9 \\
\hline
\end{tabular}

*Data are number of studies or countries

particularly in terms of usability and acceptability. Likewise, though the number of studies across the four popular application area/technology combinations always favored HICs, the presence of SMS solutions in LMICs considerably exceeded that of app solutions (27 to 3 studies), while in HICs the amount of app solutions nearly reached that of SMS solutions (49 to 64 studies). The case was similar for NCD studies in LMICs (7 SMS to 2 app solutions), yet showed no advantage for SMS solutions in HICs (30 app to 30 SMS studies).

Although eight different mHealth application areas were identified, $44.3 \%$ of studies addressed health monitoring and surveillance, $41.9 \%$ targeted health promotion and raising awareness, while only
$13.8 \%$ belonged to the remaining six application areas. The dominance of these two areas over the others indicates their higher potential success, yet also proposes a deficiency in studies addressing any of the remaining areas, particularly decision and point of care support. For the rarely targeted application areas, Table 2 shows low differences between the amounts of studies conducted in LMICs as opposed to those located in developed countries, sometimes even favoring LMICs. However, for the most popular application areas and the four application area/technology type combinations, such variations were considerably higher, even after restricting to studies that targeted NCDs. For instance, $28 \mathrm{HM}+$ app studies focused on NCDs, only $3.6 \%$ of which were located in LMICs. 
Likewise, the percentages for $\mathrm{HM}+\mathrm{SMS}$, $\mathrm{HP}+\mathrm{SMS}$, and HP+app studies were $5 \%$, $35.3 \%$, and $25 \%$ respectively. These differences indicate a demand for more NCD studies in LMICs, with SMS technology and health promotion showing more promise for acceptance.

We also must not overlook the fact that even in categories that showed relatively high percentages of studies in LMICs, many studies came from the same countries or continents, thus demonstrating limited spread of mHealth studies among LMICs compared to HICs. This becomes particularly clear when comparing the incidence of popular application areas in the main continents of HICs to LMICs. For instance, in HICs, health promotion and raising awareness studies $(n=55)$ were closely distributed among North America (45.4\%) and Europe (36.4\%), whereas studies in LMICs $(\mathrm{n}=33)$ were highly concentrated in Asia (57.6\%) compared to Africa $(27.3 \%)$. Likewise, the concentration of health monitoring and surveillance studies in HICs $(\mathrm{n}=81)$ was shared by North America (45.7\%) and Europe (34.6\%), whereas LMIC studies $(n=12)$ in Africa (41.7\%) fairly surpassed Asia (25\%). Remaining proportions in less addressed regions such as Australia, South America, and the Middle East showed relatively fewer variations. - Table 2 may indicate at the first glance a deficiency in health monitoring solutions in LMICs. However, based on the characteristics and technologies needed for studies under this area such as internet access, expensive smartphones, mobile broadband, bidirectional communication, patient monitoring devices, and technology familiarity, such solutions may not be applicable or successful in LMICs. In contrast, health promotion solutions, particularly the ones using SMS, were more likely to be found in LMICs as they made use of existing infrastructure, were relatively inexpensive, and required the most basic technology familiarity and types of phones.

The spread of mHealth was similarly limited across the four application area/ technology combinations, which comprised 30 studies in 15 LMICs. Asian countries were the most dominant, with $43.4 \%$ of studies taking place in the Asian conti- nent, $33.3 \%$ in Africa, $10 \%$ in South America, $10 \%$ in the Middle East, and $3.3 \%$ in Europe. The same dominance was observed for NCD studies $(n=9)$ conducted across six LMICs, with seven studies taking place in Asia vs. only one study in each of the Middle East (Iran) and Europe. It is not surprising that Africa and South America did not appear in these categories since the focus there is more on communicable diseases such as HIV and TB, in addition to other application areas such as data collection and communication and reporting. It is also not surprising that Europe had a minimal number of LMIC studies. However, in Middle Eastern countries, where the WHO statistics indicate 1.7 million deaths each year due to the four main NCDs alone [189], the difference is shocking.

Among the four main NCDs, mHealth studies most commonly addressed diabetes $(n=51)$, followed by CVDs $(n=24)$, respiratory diseases $(n=9)$, and cancer $(n=5)$. The amount of studies in LMICs still favored diabetes $(n=8)$, trailed by CVDs $(n=5)$, cancer $(n=3)$, and respiratory diseases $(n=1)$. In the Middle East, all four NCDs seemed to be inadequately addressed, with only two diabetes studies located in Iran, while studies for other NCDs were not identified in the region. The above WHO numbers on NCD deaths together with our review findings suggest that NCDs are potential target diseases for mHealth studies in LMICs, with diabetes appearing to be the most interesting to start with, since it has considerably exceeded other diseases in HICs, yet remains insufficiently addressed in LMICs, particularly in the Middle East.

Taking a closer look at diabetes studies appearing in our review, studies equally used SMS and apps in HICs ( $\mathrm{n}=19$ each), whereas in LMICs, both technology types were rarely employed (3 SMS vs. 1 app). This is clearly due to the fact that most diabetes solutions were complex and required two-way communication via expensive smartphones, measurement devices, and/ or access to a website; thus revealing a gap in using simple one-way SMS technology for diabetes management, and a deficiency in diabetes applications in LMICs. Similar to previous observations, the number of diabetes studies always favored HICs across the four application area/technology combinations ( Table 2). However, the category that contained the most number of studies in LMICs was HP+SMS $(n=3)$, followed by $\mathrm{HM}+\mathrm{app}(\mathrm{n}=1), \mathrm{HM}+\mathrm{SMS}$ $(\mathrm{n}=0)$, and HP+app $(\mathrm{n}=0)$. Further, these categories only involved one diabetes study in the Middle Eastern region while all remaining studies were located in Asia (India and China). Even on a smaller scale, this maintains the dominance of the Asian region among diabetes studies as well, and shows deficiency of diabetes solutions in a region with high diabetes prevalence. As the challenges of app and health monitoring solutions in LMICs have already been expressed, HP+SMS appears to be the more promising combination for diabetes. Based on the results of this review, an RCT was designed and conducted in Cairo Egypt, testing the use of SMS technology in educating and monitoring diabetic patients. Details of the study and its results will be published elsewhere.

\section{Discussion}

\subsection{Observations}

The literature results indicated that the two most popular application areas were health promotion and raising awareness and health monitoring and surveillance. Moreover, they indicated that SMS solutions were highly exceeding apps in LMICs and mostly associated with health promotion and raising awareness, while app solutions were as common as SMS in developed countries and mostly linked with health monitoring and surveillance. This contradicted the findings of the WHO report, which marked health call centers as the most commonly used initiative among Member States, and surveillance and raising awareness as the least commonly used [17]. Such contradiction, however, may be due to the fact that we only included studies that were already piloted and evaluated, while the WHO report involved any mHealth initiatives reported by Member States regardless of how developed they were. The report also mainly focused on government programs while this review retrieved clinical studies present in 
the mHealth literature, thus suggesting a gap between national initiatives and scientific studies. A great advantage of our review is in the broadness of its results. Unlike most other reviews, we did not focus on a location, application area, disease, or technology type. However, since the aim was to identify the most appropriate combination for LMICs, we divided the results into smaller categories and reported the characteristics of the most popular ones.

We identified eight mHealth application areas and seven technology types, the majority of which were health monitoring and surveillance, health promotion and raising awareness, SMS messages, and smartphone/PDA apps respectively. Remaining $\mathrm{mHealth}$ areas and technologies did not receive as much attention, which indicates greater potential for success of mHealth solutions combining one of the two popular areas with one of the two most common technologies. Participants' opinions of mHealth solutions were generally positive, yet they sometimes thought more incentives were needed to keep them motivated. Patient satisfaction with the interventions offered was commonly based on how much they enjoyed using the solution, whether they would like to continue using it, and whether they would recommend it to others. Some studies also checked if their participants could easily use the solution; if they found it helpful, useful, and understandable; and whether they preferred it to traditional methods.

Despite their intended benefits, studies in the literature suffered from a number of limitations, most commonly small sample sizes and short study durations. Accordingly, some studies failed to detect significant characteristics due to insufficient statistical power. Other studies were uncontrolled or used a historical control group, thus raising comparability concerns and requiring an RCT to confirm their findings. Recruitment sometimes occurred at a single site, or focused on a certain population or group of patients such as men, women, highly educated individuals, employees of a certain workplace, ED patients, university students, elderly individuals, or veterans; thus producing samples that were not representative of the entire population, and limiting the generalizability of the study's findings. Some studies also lacked strict randomization or randomized their groups within the same organization, leading to contamination between study groups. The reliance on self-reports and rating outcome measures using questionnaires may have raised the potential for errors in self-reported data, whereas high dropout rates may have led to imbalanced study groups or observed differences between baseline and follow-up samples.

\subsection{Limitations of the Literature Review}

Although the literature search yielded a variety of publications and contained papers that dated back to 2001, the search terms and queries may not have been broad enough to retrieve articles that were published before the term mHealth came to use. Further, only two databases were searched and the websites of ministries of health or telecommunications were not examined, which may have limited the selection of relevant studies, particularly in LMICs. The choice of IEEE Xplore may have also limited the retrieval of relevant publications, as the majority of IEEE articles focused on solution design and development rather than clinical impacts, which eventually led to their exclusion. Despite performing cross-referencing, particularly on review articles, we did not completely examine the reference lists of all the articles included. As a result, some eligible publications may have been overlooked. Finally, the review did not fully comply with the PRISMA guidelines as it was performed by only one researcher.

\section{Conclusions}

The review presented in this paper indicates that the amount of mHealth studies conducted in HICs highly surpasses LMICs. The most popular mHealth technology types are SMS messages and smartphone/PDA apps. They were almost equally used in developed countries, whereas in LMICs, the use of SMS messages highly exceeded that of smartphone/ PDA apps, thus indicating higher suitability of SMS messages in the developing world. Dominant application areas are health monitoring and surveillance and health promotion and raising awareness, with the latter more likely to exist in LMICs, particularly when using SMS. A clear deficiency is seen in studies targeting the six remaining areas, especially decision and point of care support. Compared to HICs, the spread of mHealth studies appears to be limited among LMICs, generally demonstrating high dominance of the Asian region. Diabetes appears to be the most commonly addressed medical condition, yet remains inadequately targeted in LMICs together with the other main NCDs.

It is clearly essential that future mHealth studies attempt to move away from areas such as health monitoring and surveillance and health promotion and raising awareness to the six least commonly addressed application areas. Further, studies should target other NCDs such as cancer, respiratory diseases, and CVDs rather than diabetes, obesity, and health behaviors. In LMICs, the spread of the popular application areas and mHealth technologies needs to extend beyond Asian countries, particularly for NCDs and diabetes. The Middle East, though a region with high prevalence of NCDs and widespread of mobile communication technologies, suffers from a dearth of mHealth literature. Governments are encouraged to cooperate with organizations such as the WHO in order to facilitate research protocols and funds, and produce necessary publications. Given the extended availability and affordability of smartphones in recent years, LMICs are also encouraged to uptake app and health monitoring solutions, taking into account the necessity of providing proper user training and adhering to easyto-use applications.

\section{References}

1. Mahmud N, Rodriguez J, Nesbit J. A text messagebased intervention to bridge the healthcare communication gap in the rural developing world Technol Health Care 2010; 18(2): 137-144

2. Vatsalan D, Arunatileka S, Chapman K, Senaviratne G, Sudahar S, Wijetileka D, et al. Mobile technologies for enhancing eHealth solutions in developing countries. In: Finkelstein J, Ossebaard H, van Gemert-Pijnen L, editors. eTELEMED 2010: 
Proceedings of the 2nd International Conference on eHealth, Telemedicine, and Social Medicine; 2010 Feb 10-16; St. Maarten, Netherlands Antilles. IEEE Computer Society; 2010. p. 84-89.

3. Littman-Quinn R, Chandra A, Schwartz A, Chang A, Fadlelmola F, Ghose S, et al. mHealth applications for clinical education, decision making, and patient adherence in Botswana. In: 2011 ISTAfrica: Proceedings of the IST-Africa Conference; 2011 May 11-13; Gaborone, Botswana. IIMC International Information Management Corporation; 2011. p. 1-8.

4. Ngabo F, Nguimfack J, Nwaigwe F, Mugeni C, Muhoza D, Wilson D, et al. Designing and Implementing an Innovative SMS-based alert system (RapidSMS-MCH) to monitor pregnancy and reduce maternal and child deaths in Rwanda. Pan Afr Med J 2012; 13: 31.

5. Mechael P. Mobile phones and the preservation of well-being in Egyptian families [Internet]. 2007 [cited 2012 June 17]. Available from: http:// www-personal.umich.edu/ parkyo/site/ paper\%20abstracts/PatriciaMechaelMobile PhonesWellBeingEgypt2.pdf.

6. Lemay N, Sullivan T, Jumbe B, Perry C. Reaching remote health workers in Malawi: baseline assessment of a pilot mHealth intervention. J Health Commun 2012; 17 Suppl 1: 105-117.

7. World Health Organization. mHealth: New horizons for health through mobile technologies. Geneva: World Health Organization; 2011 World Health Organization. Available from: http://www. who.int/goe/publications/goe_mhealth_web.pdf.

8. Iwaya L, Gomes M, Simplício M, Carvalho T, Dominicini C, Sakuragui R, et al. Mobile health in emerging countries: A survey of research initiatives in Brazil. Int J Med Inform 2013; 82(5): 283-298.

9. Akter S, Ray P. mHealth - an Ultimate Platform to Serve the Unserved. Yearb Med Inform 2010: 94-100.

10. Vital Wave Consulting. mHealth for Development: The Opportunity of Mobile Technology for Healthcare. Washington, D.C. and Berkshire, UK: UN Foundation-Vodafone Foundation Partnership; 2009. Available from: http://www.globalprob lems-globalsolutions-files.org/unf_website/assets/ publications/technology/mhealth/ mHealth_for_Development_full.pdf.

11. International Telecommunication Union. Mobile eHealth solutions for Developing Countries. Geneva: International Telecommunication Union; 2010. Available from: http://www.itu.int/ dms_pub/itu-d/opb/stg/D-STGSG02.14.2-2010-PDF-E.pdf.

12. Chib A, Wilkin H, Ling L, Hoefman B, Van Biejma $\mathrm{H}$. You have an important message! Evaluating the effectiveness of a text message HIV/AIDS campaign in Northwest Uganda. J Health Commun 2012; 17 Suppl 1: 146-157.

13. Parker R, Dmitrieva E, Frolov S, Gazmararian J. Text4baby in the United States and Russia: an opportunity for understanding how mHealth affects maternal and child health. J Health Commun 2012; 17 Suppl 1:30-36.

14. Rajput Z, Mbugua S, Amadi D, Chepngeno V, Saleem J, Anokwa Y, et al. Evaluation of an Androidbased mHealth system for population surveillance in developing countries. J Am Med Inform Assoc 2012; 19(4): 655-659.

15. Katz R, Mesfin T, Barr K. Lessons from a community-based mHealth diabetes self-management program: "it's not just about the cell phone". J Health Commun 2012; 17 Suppl 1: 67-72.

16. Nayyar G. How to manage diabetes - not be managed by it. mHealth solutions are paving the way toward better disease management. Health Manag Technol 2012; 33(12): 14-15.

17. Fokkenrood H, Lauret G, Scheltinga M, Spreeuwenberg C, de Bie R, Teijink J. Multidisciplinary treatment for peripheral arterial occlusive disease and the role of eHealth and mHealth. J Multidiscip Healthc 2012; 5: 257-263.

18. Mattila E, Pärkkä J, Hermersdorf M, Kaasinen J, Vainio J, Samposalo K, et al. Mobile Diary for Wellness Management: Results on Usage and Usability in Two User Studies. IEEE Trans Inf Technol Biomed 2008; 12(4): 501-512.

19. Ghorai K, Saha S, Bakshi A, Mahanti A, Ray P. An mHealth Recommender for Smoking Cessation Using Case Based Reasoning. In: Sprague R, editor. HICSS 2013: Proceedings of the 46th Hawaii International Conference on System Sciences; 2013 Jan 7-10; Grand Wailea, Maui, Hawaii. IEEE Computer Society; 2013. p. 2695-2704.

20. Fjeldsoe B, Miller Y, O’Brien J, Marshall A. Iterative development of MobileMums: a physical activity intervention for women with young children. Int J Behav Nutr Phys Act 2012; 9: 151.

21. Fukuoka Y, Komatsu J, Suarez L, Vittinghoff E, Haskell W, Noorishad T, et al. The mPED randomized controlled clinical trial: applying mobile persuasive technologies to increase physical activity in sedentary women protocol. BMC Public Health 2011; 11: 933.

22. Earth Institute. Barriers and Gaps Affecting mHealth in Low and Middle Income Countries: A Policy White Paper. Washington, D.C.: mHealth Alliance; $2010 . \quad$ Available from: http://cgsd.columbia.edu/files/2012/11/mHealth BarriersWhitePaperFINAL.pdf.

23. Mechael P, Sloninsky D. Towards the Development of an mHealth Strategy: A Literarture Review. Geneva: World Health Organization; 2008 August World Health Organization. Available from: http://www.who.int/goe/mobile_health/mHealth Review_Aug09.pdf.

24. Chang LW, Kagaayi J, Arem H, Nakigozi G, Ssempijja V, Serwadda D, et al. Impact of a mHealth intervention for peer health workers on AIDS care in rural Uganda: a mixed methods evaluation of a cluster-randomized trial. AIDS Behav 2011; 15(8): 1776-1784.

25. Seidenberg P, Nicholson S, Schaefer M, Semrau K, Bweupe M, Masese N, et al. Early infant diagnosis of HIV infection in Zambia through mobile phone texting of blood test results. Bulletin of the World Health Organization 2012; 90: 348-356.

26. Leventhal R. How a N.J. medical center saved millions with mHealth technology. Healthc Inform 2014; 31(5): 30-35.

27. Neupane S, Odendaal W, Friedman I, Jassat W, Schneider H, Doherty T. Comparing a paper based monitoring and evaluation system to a mHealth system to support the national community health worker programme, South Africa: an evaluation. BMC Med Inform Decis Mak 2014; 14: 69.
28. Odigie VI, Yusufu LM, Dawotola DA, Ejagwulu F, Abur P, Mai A, et al. The mobile phone as a tool in improving cancer care in Nigeria. Psychooncology 2012; 21(3): 332-335.

29. Schooley B, San Nicolas-Rocca T, Burkhard R. Patient-provider communications in outpatient clinic settings: a clinic-based evaluation of mobile device and multimedia mediated communications for patient education. JMIR Mhealth Uhealth 2015; 3(1): e2.

30. Jandee K, Kaewkungwal J, Khamsiriwatchara A, Lawpoolsri S, Wongwit W, Wansatid P. Effectiveness of Using Mobile Phone Image Capture for Collecting Secondary Data: A Case Study on Immunization History Data Among Children in Remote Areas of Thailand. JMIR Mhealth Uhealth 2015; 3(3): e75.

31. Ranck J. Time to get mHealth moving. [Internet]. 2011 [cited 2016 Sept 26]. Available from: http://www.scidev.net/global/health/opinion/ time-to-get-mhealth-moving-1.html.

32. Surka S, Edirippulige S, Steyn K, Gaziano T, Puoane T, Levitt N. Evaluating the use of mobile phone technology to enhance cardiovascular disease screening by community health workers. Int J Med Inform 2014; 83(9): 648-654.

33. Somers TJ, Abernethy AP, Edmond SN, Kelleher SA, Wren AA, Samsa GP, et al. A Pilot Study of a Mobile Health Pain Coping Skills Training Protocol for Patients with Persistent Cancer Pain. J Pain Symptom Manage 2015; 50(4): 553-558.

34. Becevic M, Anderson B, Ginger Han J, Mutrux ER, Hicks L, Edison K, et al. TeleMDID: Mobile technology applications for interactive diagnoses in teledermatology clinics. In: 2013 IEEE 15th International Conference on e-Health Networking, Applications \& Services (Healthcom); 2013; Lisbon. p. 429-33. Available from: http://ieeexplore.ieee.org/document/6720714/.

35. Kingue S, Angandji P, Menanga AP, Ashuntantang G, Sobngwi E, Dossou-Yovo RA, et al. Efficiency of an intervention package for arterial hypertension comprising telemanagement in a Cameroonian rural setting: the TELEMEDCAM study. Pan Afr Med J 2013; 15: 153.

36. Yamada KC, Inoue S, Sakamoto Y. An effective support system of emergency medical services with tablet computers. JMIR Mhealth Uhealth 2015; 3(1): e23.

37. Chen H, Dingcheng X, Weiyi Q, Minwei Z, Yan T, Jian L, et al. A study of regional cooperative emergency care system for ST-elevation myocardial infarction patients based on the internet of things. In: 2012 IEEE 14th International Conference on e-Health Networking, Applications and Services (Healthcom); 2012; Beijing, China. p. 73-77. Available from: http://ieeexplore.ieee.org/ document/6380069/.

38. Murad A, Schooley B, Horan T, Abed Y. Enabling Patient Information Handoff from Pre-hospital Transport Providers to Hospital Emergency Departments: Design-Science Approach to Field Testing. In: 2014 47th Hawaii International Conference on System Sciences (HICSS); 2014; Hawaii. p. 2665-2674. Available from: http://ieeexplore.ieee.org/document/6758936/.

39. Galligioni E, Piras EM, Galvagni M, Eccher C, Caramatti S, Zanolli D, et al. Integrating mHealth 
in Oncology: Experience in the Province of Trento. J Med Internet Res 2015; 17(5): e114.

40. Rubin MN, Fugate JE, Barrett KM, Rabinstein AA, Flemming KD. An acute stroke evaluation app: a practice improvement project. Neurohospitalist 2015; 5(2): 63-69.

41. Kuntagod N, Paul S, Kumaresan S, Balasubramaniam B, Ahmed I. Connected vision care for eradication of preventable blindness. In: 2015 IEEE International Symposium on Medical Measurements and Applications (MeMeA); 2015; Torino, Italy. p. 202-207. Available from: http://ieeexplore.ieee.org/document/7145199/.

42. Quinn CC, Clough SS, Minor JM, Lender D, Okafor MC, Gruber-Baldini A. WellDoc mobile diabetes management randomized controlled trial: change in clinical and behavioral outcomes and patient and physician satisfaction. Diabetes Technol Ther 2008; 10(3): 160-168.

43. Cafazzo JA, Casselman M, Hamming N, Katzman DK, Palmert MR. Design of an mHealth app for the self-management of adolescent type 1 diabetes: a pilot study. J Med Internet Res 2012; 14(3): e70.

44. Lehocki F, Balogh Š, Žákovičová E, Kováč M, de Witte B. Innovative telemedicine solutions for diabetic patients. In: Conference on Biomedical Engineering and Sciences (IECBES), 2012 IEEE EMBS; 2012. Available from: http://ieeexplore.ieee.org/document/6498185/.

45. DeSalvo DJ, Keith-Hynes P, Peyser T, Place J, Caswell $\mathrm{K}$, Wilson DM, et al. Remote glucose monitoring in cAMP setting reduces the risk of prolonged nocturnal hypoglycemia. Diabetes Technol Ther 2014; 16(1): 1-7.

46. Kirwan M, Vandelanotte C, Fenning A, Duncan MJ. Diabetes self-management smartphone application for adults with type 1 diabetes: randomized controlled trial. J Med Internet Res 2013; 15(11): e235.

47. Turner J, Larsen M, Tarassenko L, Neil A, Farmer A. Implementation of telehealth support for patients with type 2 diabetes using insulin treatment: An exploratory study. Informatics in Primary Care 2009; 17(1): 47-53.

48. Gómez EJ, Hernando ME, García A, Del Pozo F, Cermeño J, Corcoy R, et al. Telemedicine as a tool for intensive management of diabetes: the DIABTel experience. Comput Methods Programs Biomed 2002; 69(2): 163-177.

49. Kollmann A, Riedl M, Kastner P, Schreier G, Ludvik B. Feasibility of a mobile phone-based data service for functional insulin treatment of type 1 diabetes mellitus patients. J Med Internet Res 2007; 9(5): e36.

50. Vähätalo MA, Virtamo HE, Viikari JS, Rönnemaa T. Cellular phone transferred self blood glucose monitoring: Prerequisites for positive outcome. Pract Diabetes Int 2003; 21(5): 192-194.

51. Larsen ME, Turner J, Farmer A, Neil A, Tarassenko L. Telemedicine-supported insulin optimisation in primary care. J Telemed Telecare 2010; 16(8): 433-440.

52. Petrella RJ, Stuckey MI, Shapiro S, Gill DP. Mobile health, exercise and metabolic risk: a randomized controlled trial. BMC Public Health 2014; 14: 1082.

53. Koehler F, Winkler S, Schieber M, Sechtem U, Stangl K, Böhm M, et al. Impact of remote telemedical management on mortality and hospitaliz- ations in ambulatory patients with chronic heart failure: the telemedical interventional monitoring in heart failure study. Circulation 2011; 123(17): 1873-1880

54. Dendale P, De Keulenaer G, Troisfontaines P, Weytjens C, Mullens W, Elegeert I, et al. Effect of a telemonitoring-facilitated collaboration between general practitioner and heart failure clinic on mortality and rehospitalization rates in severe heart failure: the TEMA-HF 1 (TElemonitoring in the MAnagement of Heart Failure) study. Eur J Heart Fail 2012; 14(3): 333-340.

55. Madsen LB, Kirkegaard P, Pedersen EB. Blood pressure control during telemonitoring of home blood pressure. A randomized controlled trial during 6 months. Blood Press 2008; 17(2): 78-86.

56. Seto E, Leonard KJ, Cafazzo JA, Barnsley J, Masino C, Ross HJ. Mobile phone-based telemonitoring for heart failure management: a randomized controlled trial. J Med Internet Res 2012; 14(1): e31.

57. Logan AG, Irvine MJ, McIsaac WJ, Tisler A, Rossos PG, Easty A, et al. Effect of home blood pressure telemonitoring with self-care support on uncontrolled systolic hypertension in diabetics. Hypertension 2012; 60(1): 51-57.

58. Logan AG, McIsaac WJ, Tisler A, Irvine MJ, Saunders A, Dunai A. Mobile phone-based remote patient monitoring system for management of hypertension in diabetic patients. American Journal Of Hypertension 2007; 20(9): 942-948.

59. Worringham C, Rojek A, Stewart I. Development and feasibility of a smartphone, ECG and GPS based system for remotely monitoring exercise in cardiac rehabilitation. PLoS One 2011; 6: el4669.

60. Liu WT, Wang CH, Lin HC, Lin SM, Lee KY, Lo YL, et al. Efficacy of a cell phone-based exercise programme for COPD. Eur Respir J 2008; 32(3): 651-659.

61. Ryan D, Price D, Musgrave SD, Malhotra S, Lee AJ, Ayansina D, et al. Clinical and cost effectiveness of mobile phone supported self monitoring of asthma: multicentre randomised controlled trial. BMJ 2012; 344: e1756.

62. Brindal E, Hendrie G, Freyne J, Coombe M, Berkovsky S, Noakes M. Design and pilot results of a mobile phone weight-loss application for women starting a meal replacement programme. I Telemed Telecare 2013; 19: 166-174.

63. Carter MC, Burley VJ, Nykjaer C, Cade JE. Adherence to a smartphone application for weight loss compared to website and paper diary: pilot randomized controlled trial. J Med Internet Res 2013; 15(4): e32.

64. Turner-McGrievy GM, Tate DF. Are we sure that Mobile Health is really mobile? An examination of mobile device use during two remotely-delivered weight loss interventions. Int J Med Inform 2014; 83(5): 313-319.

65. Turner-McGrievy GM, Beets MW, Moore JB, Kaczynski AT, Barr-Anderson DJ, Tate DF. Comparison of traditional versus mobile app selfmonitoring of physical activity and dietary intake among overweight adults participating in an mHealth weight loss program. J Am Med Inform Assoc 2013; 20(3): 513-518.

66. Beasley JM, Riley WT, Davis A, Singh J. Evaluation of a PDA-based dietary assessment and intervention program: a randomized controlled trial. J Am Coll Nutr 2008; 27(2): 280-286.
67. Burke LE, Styn MA, Sereika SM, Conroy MB, Ye L, Glanz K. Using mHealth technology to enhance self-monitoring for weight loss: a randomized trial. Am J Prev Med 2012; 43(1): 20-26.

68. Spring B, Duncan JM, Janke EA, Kozak AT, McFadden HG, DeMott A. Integrating technology into standard weight loss treatment: a randomized controlled trial. JAMA Internal Medicine 2013; 173(2): 105-111.

69. Cushing CC, Jensen CD, Steele RG. An evaluation of a personal electronic device to enhance selfmonitoring adherence in a pediatric weight management program using a multiple baseline design. J Pediatr Psychol 2011; 36(3): 301-307.

70. Brath H, Morak J, Kästenbauer T, Modre-Osprian R, Strohner-Kästenbauer H, Schwarz M, et al. Mobile health (mHealth) based medication adherence measurement - a pilot trial using electronic blisters in diabetes patients. Br J Clin Pharmacol 2013; 76 Suppl 1: 47-55.

71. Patel S, Jacobus-Kantor L, Marshall L, Ritchie C, Kaplinski M, Khurana PS, et al. Mobilizing your medications: an automated medication reminder application for mobile phones and hypertension medication adherence in a high-risk urban population. J Diabetes Sci Technol 2013; 7(3): 630-639.

72. Gamito P, Oliveira J, Lopes P, Brito R, Morais D, Silva D, et al. Executive functioning in alcoholics following an mHealth cognitive stimulation program: randomized controlled trial. J Med Internet Res 2014; 16(4): e102.

73. Gustafson DH, McTavish FM, Chih MY, Atwood AK, Johnson RA, Boyle MG, et al. A smartphone application to support recovery from alcoholism: a randomized clinical trial. JAMA Psychiatry 2014; 71(5): 566-572.

74. Ben-Zeev D, Brenner CJ, Begale M, Duffecy J, Mohr DC, Mueser KT. Feasibility, acceptability, and preliminary efficacy of a smartphone intervention for schizophrenia. Schizophr Bull 2014; 40(6): 1244-1253.

75. da Costa TM, Barbosa BJ, Gomes e Costa DA, Sigulem D, de Fátima Marin H, Filho AC, et al. Results of a randomized controlled trial to assess the effects of a mobile SMS-based intervention on treatment adherence in HIV/AIDS-infected Brazilian women and impressions and satisfaction with respect to incoming messages. Int J Med Inform 2012; 81(4): 257-269.

76. Hardy H, Kumar V, Doros G, Farmer E, Drainoni ML, Rybin D, et al. Randomized controlled trial of a personalized cellular phone reminder system to enhance adherence to antiretroviral therapy. AIDS Patient Care STDS 2011; 25(3): 153-161.

77. Hou MY, Hurwitz S, Kavanagh E, Fortin J, Goldberg $A B$. Using daily text-message reminders to improve adherence with oral contraceptives: a randomized controlled trial. Obstet Gynecol 2010; 116(3): 633-640.

78. Park LG, Howie-Esquivel J, Chung ML, Dracup K. A text messaging intervention to promote medication adherence for patients with coronary heart disease: a randomized controlled trial. Patient Educ Couns 2014; 94(2): 261-268.

79. Park LG, Howie-Esquivel J, Whooley MA, Dracup K. Psychosocial factors and medication adherence among patients with coronary heart disease: A text messaging intervention. Eur J Cardiovasc Nurs 2015; 14(3): 264-273. 
80. Pop-Eleches C, Thirumurthy H, Habyarimana JP, Zivin JG, Goldstein MP, de Walque D, et al. Mobile phone technologies improve adherence to antiretroviral treatment in a resource-limited setting: a randomized controlled trial of text message reminders. AIDS 2011; 25(6): 825-834.

81. Foreman K, Stockl K, Le L, Fisk E, Shah S, Lew H, et al. Impact of a text messaging pilot program on patient medication adherence. Clin Ther 2012; 34(5): 1084-1091.

82. Lester RT, Ritvo P, Mills EJ, Kariri A, Karanja S, Chung MH, et al. Effects of a mobile phone short message service on antiretroviral treatment adherence in Kenya (WelTel Kenya1): a randomised trial. Lancet 2010; 376(9755): 1838-1845.

83. Lewis MA, Uhrig JD, Bann CM, Harris JL, Furberg $\mathrm{RD}$, Coomes $\mathrm{C}$, et al. Tailored text messaging intervention for HIV adherence: a proof-of-concept study. Health Psychol 2013; 32(3): 248-253.

84. Iribarren S, Beck S, Pearce PF, Chirico C, Etchevarria M, Cardinale D, et al. TextTB: A Mixed Method Pilot Study Evaluating Acceptance, Feasibility, and Exploring Initial Efficacy of a Text Messaging Intervention to Support TB Treatment Adherence. Tuberc Res Treat 2013; 2013: 349394.

85. Cocosila M, Archer N, Haynes RB, Yuan Y. Can wireless text messaging improve adherence to preventive activities? Results of a randomised controlled trial. Int J Med Inform 2009; 78(4): 230-238.

86. Miloh T, Annunziato R, Arnon R, Warshaw J, Parkar S, Suchy F, et al. Improved adherence and outcomes for pediatric liver transplant recipients by using text messaging. Pediatrics 2009; 124(5): e844-850.

87. Dick JJ, Nundy S, Solomon MC, Bishop KN, Chin MH, Peek ME. Feasibility and usability of a text message-based program for diabetes self-management in an urban African-American population. J Diabetes Sci Technol 2011; 5(5): 1246-1254.

88. de Niet J, Timman R, Bauer S, van den Akker E, Buijks $\mathrm{H}$, de Klerk $\mathrm{C}$, et al. The effect of a short message service maintenance treatment on body mass index and psychological well-being in overweight and obese children: a randomized controlled trial. Pediatr Obes 2012; 7(3): 205-219.

89. de Niet J, Timman R, Bauer S, van den Akker E, de Klerk C, Kordy H, et al. Short message service reduces dropout in childhood obesity treatment: a randomized controlled trial. Health Psychol 2012; 31(6): 797-805

90. Bauer S, de Niet J, Timman R, Kordy H. Enhancement of care through self-monitoring and tailored feedback via text messaging and their use in the treatment of childhood overweight. Patient Educ Couns 2010; 79(3): 315-319.

91. Hanauer DA, Wentzell K, Laffel N, Laffel LM. Computerized Automated Reminder Diabetes System (CARDS): e-mail and SMS cell phone text messaging reminders to support diabetes management. Diabetes Technol Ther 2009; 11(2): 99-106.

92. Kim HS, Jeong HS. A nurse short message service by cellular phone in type-2 diabetic patients for six months. J Clin Nurs 2007; 16(6): 1082-1087.

93. Yoon KH, Kim HS. A short message service by cellular phone in type 2 diabetic patients for 12 months. Diabetes Res Clin Pract 2008; 79(2): 256-261.
94. Kim HS. A randomized controlled trial of a nurse short-message service by cellular phone for people with diabetes. Int J Nurs Stud 2007; 44(5): 687-692.

95. Kim C, Kim H, Nam J, Cho M, Park J, Kang E, et al. Internet diabetic patient management using a short messaging service automatically produced by a knowledge matrix system. Diabetes Care 2007;3 0(11): 2857-2858.

96. Kim HS, Kim NC, Ahn SH. Impact of a nurse short message service intervention for patients with diabetes. J Nurs Care Qual 2006; 21(3): 266-271.

97. Kwon HS, Cho JH, Kim HS, Lee JH, Song BR, Oh JA, et al. Development of web-based diabetic patient management system using short message service (SMS). Diabetes Res Clin Pract 2004; 66 Suppl 1: S133-137.

98. Kim SI, Kim HS. Effectiveness of mobile and internet intervention in patients with obese type 2 diabetes. Int J Med Inform 2008; 77(6): 399-404.

99. Kim CS, Park SY, Kang JG, Lee SJ, Ihm SH, Choi MG, et al. Insulin dose titration system in diabetes patients using a short messaging service automatically produced by a knowledge matrix. Diabetes Technol Ther 2010; 12(8): 663-669.

100. Benhamou PY, Melki V, Boizel R, Perreal F, Quesada JL, Bessieres-Lacombe S, et al. One-year efficacy and safety of Web-based follow-up using cellular phone in type 1 diabetic patients under insulin pump therapy: the PumpNet study. Diabetes Metab 2007; 33(3): 220-226.

101. Cho JH, Lee HC, Lim DJ, Kwon HS, Yoon KH. Mobile communication using a mobile phone with a glucometer for glucose control in Type 2 patients with diabetes: as effective as an Internetbased glucose monitoring system. J Telemed Telecare 2009; 15(2): 77-82.

102. Faridi Z, Liberti L, Shuval K, Northrup V, Ali A, Katz DL. Evaluating the impact of mobile telephone technology on type 2 diabetic patients' self-management: the NICHE pilot study. J Eval Clin Pract 2008; 14(3): 465-469.

103. Harno K, Kauppinen-Mäkelin R, Syrjäläinen J. Managing diabetes care using an integrated regional ehealth approach. J Telemed Telecare 2006; 12 Suppl 1: 13-15.

104. Lim S, Kang SM, Shin H, Lee HJ, Won Yoon J, Yu $\mathrm{SH}$, et al. Improved glycemic control without hypoglycemia in elderly diabetic patients using the ubiquitous healthcare service, a new medical information system. Diabetes Care 2011; 34(2): 308-313.

105. Blasco A, Carmona M, Fernández-Lozano I, Salvador CH, Pascual M, Sagredo PG, et al. Evaluation of a telemedicine service for the secondary prevention of coronary artery disease. J Cardiopulm Rehabil Prev 2012; 32(1): 25-31.

106. Carrasco MP, Salvador CH, Sagredo PG, Márquez-Montes J, González de Mingo MA, Fragua JA, et al. Impact of patient-general practitioner short-messages-based interaction on the control of hypertension in a follow-up service for low-tomedium risk hypertensive patients: a randomized controlled trial. IEEE Trans Inf Technol Biomed 2008; 12(6): 780-791.

107. Kiselev AR, Gridnev VI, Shvartz VA, Posnenkova OM, Dovgalevsky PY. Active ambulatory care management supported by short message services and mobile phone technology in patients with arterial hypertension. J Am Soc Hypertens 2012; 6(5): 346-355.

108. Ostojic V, Cvoriscec B, Ostojic SB, Reznikoff D, Stipic-Markovic A, Tudjman Z. Improving asthma control through telemedicine: a study of short-message service. Telemed J E Health 2005; 11(1): 28-35.

109. Prabhakaran L, Chee WY, Chua KC, Abisheganaden J, Wong WM. The use of text messaging to improve asthma control: a pilot study using the mobile phone short messaging service (SMS). J Telemed Telecare 2010; 16(5): 286-290.

110. Aguilera A, Berridge C. Qualitative feedback from a text messaging intervention for depression: benefits, drawbacks, and cultural differences. JMIR Mhealth Uhealth 2014; 2(4): e46.

111. Komatsu H, Sekine Y, Okamura N, Kanahara N, Okita K, Matsubara S. Effectiveness of Information Technology Aided Relapse Prevention Programme in Schizophrenia excluding the effect of user adherence: a randomized controlled trial. Schizophr Res 2013; 150(1): 240-244.

112. Spaniel F, Vohlídka P, Hrdlicka J, Kozený J, Novák T, Motlová L, et al. ITAREPS: information technology aided relapse prevention programme in schizophrenia. Schizophr Res 2008; 98(1-3): 312-317.

113. Spaniel F, Vohlídka P, Kozený J, Novák T, Hrdlicka J, Motlová L, et al. The Information Technology Aided Relapse Prevention Programme in Schizophrenia: an extension of a mirror-design follow-up. Int J Clin Pract 2008; 62(12): 1943-1946.

114. Siedner MJ, Santorino D, Haberer JE, Bangsberg DR. Know your audience: predictors of success for a patient-centered texting app to augment linkage to HIV care in rural Uganda. J Med Internet Res 2015; 17(3): e78.

115. da Costa TM, Salomão PL, Martha AS, Pisa IT, Sigulem $\mathrm{D}$. The impact of short message service text messages sent as appointment reminders to patients' cell phones at outpatient clinics in São Paulo, Brazil. Int J Med Inform 2010; 79(1): 65-70.

116. Lin H, Chen W, Luo L, Congdon N, Zhang X, Zhong $\mathrm{X}$, et al. Effectiveness of a short message reminder in increasing compliance with pediatric cataract treatment: a randomized trial. Ophthalmology 2012; 119(12): 2463-2470.

117. Sims H, Sanghara H, Hayes D, Wandiembe S, Finch $\mathrm{M}$, Jakobsen $\mathrm{H}$, et al. Text message reminders of appointments: a pilot intervention at four community mental health clinics in London. Psychiatr Serv 2012; 63(2): 161-168.

118. Prasad S, Anand R. Use of mobile telephone short message service as a reminder: the effect on patient attendance. Int Dent J 2012; 62(1): 21-26.

119. Vilella A, Bayas JM, Diaz MT, Guinovart C, Diez C, Simó D, et al. The role of mobile phones in improving vaccination rates in travelers. Prev Med 2004; 38(4): 503-509.

120. Mushamiri I, Luo C, Iiams-Hauser C, Ben Amor Y. Evaluation of the impact of a mobile health system on adherence to antenatal and postnatal care and prevention of mother-to-child transmission of HIV programs in Kenya. BMC Public Health 2015; 15: 102. 
121. Khokhar A. Short text messages (SMS) as a reminder system for making working women from Delhi Breast Aware. Asian Pac J Cancer Prev 2009; 10(2): 319-322.

122. Kaewkungwal J, Singhasivanon P, Khamsiriwatchara A, Sawang S, Meankaew P, Wechsart A. Application of smart phone in "Better Border Healthcare Program": a module for mother and child care. BMC Med Inform Decis Mak 2010; 10: 69.

123. Trent M, Tomaszewski K. Family planning appointment attendance among urban youth: results from the depotext trial. Journal of Adolescent Health 2013; 52(2): S88

124. Márquez Contreras E, de la Figuera von Wichmann M, Gil Guillén V, Ylla-Catalá A, Figueras $M$, Balaña $M$, et al. Effectiveness of an intervention to provide information to patients with hypertension as short text messages and reminders sent to their mobile phone (HTA-Alert). Aten Primaria 2004; 34(8): 399-405.

125. Khonsari S, Subramanian P, Chinna K, Latif LA, Ling LW, Gholami O. Effect of a reminder system using an automated short message service on medication adherence following acute coronary syndrome. Eur J Cardiovasc Nurs 2015; 14(2): 170-179.

126. Ollivier L, Romand O, Marimoutou C, Michel R, Pognant C, Todesco A, et al. Use of short message service (SMS) to improve malaria chemoprophylaxis compliance after returning from a malaria endemic area. Malar J 2009; 8: 236.

127. Montes JM, Medina E, Gomez-Beneyto M, Maurino J. A short message service (SMS)-based strategy for enhancing adherence to antipsychotic medication in schizophrenia. Psychiatry Res 2012; 200(2-3): 89-95.

128. Strandbygaard U, Thomsen SF, Backer V. A daily SMS reminder increases adherence to asthma treatment: a three-month follow-up study. Respir Med 2010; 104(2): 166-171.

129. Shetty AS, Chamukuttan S, Nanditha A, Raj RK, Ramachandran A. Reinforcement of adherence to prescription recommendations in Asian Indian diabetes patients using short message service (SMS) - a pilot study. J Assoc Physicians India 2011; 59: 711-714.

130. Kim JY, Oh S, Steinhubl S, Kim S, Bae WK, Han JS, et al. Effectiveness of 6 months of tailored text message reminders for obese male participants in a worksite weight loss program: randomized controlled trial. JMIR Mhealth Uhealth 2015; 3(1): e14.

131. Lv Y, Zhao H, Liang Z, Dong H, Liu L, Zhang D, et al. A mobile phone short message service improves perceived control of asthma: a randomized controlled trial. Telemed J E Health 2012; 18(6): 420-426.

132. Zurovac D, Sudoi RK, Akhwale WS, Ndiritu M, Hamer DH, Rowe AK, et al. The effect of mobile phone text-message reminders on Kenyan health workers' adherence to malaria treatment guidelines: a cluster randomised trial. Lancet 2011; 378(9793): 795-803.

133. Evans W, Nielsen PE, Szekely DR, Bihm JW, Murray $\mathrm{EA}$, Snider J, et al. Dose-response effects of the text4baby mobile health program: randomized controlled trial. JMIR Mhealth Uhealth 2015; 3(1): e12.
134. Evans WD, Wallace Bihm J, Szekely D, Nielsen P, Murray E, Abroms L, et al. Initial outcomes from a 4-week follow-up study of the Text4baby program in the military women's population: randomized controlled trial. J Med Internet Res 2014; 16(5): e131.

135. Sharma R, Hebbal M, Ankola AV, Murugabupathy V. Mobile-phone text messaging (SMS) for providing oral health education to mothers of preschool children in Belgaum City. J Telemed Telecare 2011; 17(8): 432-436.

136. Lund S, Rasch V, Hemed M, Boas IM, Said A, Said K, et al. Mobile phone intervention reduces perinatal mortality in zanzibar: secondary outcomes of a cluster randomized controlled trial. JMIR Mhealth Uhealth 2014; 2(1): e15.

137. Sheoran B, Braun RA, Gaarde JP, Levine DK. The hookup: collaborative evaluation of a youth sexual health program using text messaging technology. JMIR Mhealth Uhealth 2014; 2(4): e51.

138. Hoefman B, Apunyo B. Using SMS for HIV/AIDS education and to expand the use of HIV testing and counselling services at the AIDS Information Centre (AIC) Uganda. In: M4D 2010; 2010; Kampala, Uganda. p. 40-0. Available from: http://www.bibalex.org/Search4Dev/ files/394695/336588.pdf.

139. de Tolly K, Skinner D, Nembaware V, Benjamin P. Investigation into the use of short message services to expand uptake of human immunodeficiency virus testing, and whether content and dosage have impact. Telemed J E Health 2012; 18(1): 18-23.

140. Suffoletto B, Calabria J, Ross A, Callaway C, Yealy DM. A mobile phone text message program to measure oral antibiotic use and provide feedback on adherence to patients discharged from the emergency department. Acad Emerg Med 2012; 19(8): 949-958.

141. Arora S, Peters AL, Burner E, Lam CN, Menchine M. Trial to examine text message-based mHealth in emergency department patients with diabetes (TExT-MED): a randomized controlled trial. Ann Emerg Med 2014; 63(6): 745-754.

142. Arora S, Peters AL, Agy C, Menchine M. A mobile health intervention for inner city patients with poorly controlled diabetes: proof-of-concept of the TExT-MED program. Diabetes Technol Ther 2012; 14(6): 492-496.

143. Nundy S, Dick JJ, Chou CH, Nocon RS, Chin $\mathrm{MH}$, Peek ME. Mobile phone diabetes project led to improved glycemic control and net savings for Chicago plan participants. Health Aff (Millwood) 2014; 33(2): 265-272.

144. Goodarzi M, Ebrahimzadeh I, Rabi A, Saedipoor B, Jafarabadi MA. Impact of distance education via mobile phone text messaging on knowledge, attitude, practice and self efficacy of patients with type 2 diabetes mellitus in Iran. J Diabetes Metab Disord 2012; 11(1): 1-8.

145. Lua PL, Neni WS. A randomised controlled trial of an SMS-based mobile epilepsy education system. J Telemed Telecare 2013; 19(1): 23-28.

146. Mehran L, Nazeri P, Delshad H, Mirmiran P, Mehrabi Y, Azizi F. Does a text messaging intervention improve knowledge, attitudes and practice regarding iodine deficiency and iodized salt consumption? Public Health Nutr 2012; 15(12): $2320-2325$.
147. Seid M, D’Amico EJ, Varni JW, Munafo JK, Britto MT, Kercsmar CM. The in vivo adherence intervention for at risk adolescents with asthma: report of a randomized pilot trial. J Pediatr Psychol 2012; 37(4): 390-403.

148. Balato N, Megna M, Di Costanzo L, Balato A, Ayala F. Educational and motivational support service: a pilot study for mobile-phone-based interventions in patients with psoriasis. Br J Dermatol 2013; 168(1): 201-205.

149. Markowitz JT, Cousineau T, Franko DL, Schultz AT, Trant M, Rodgers R, et al. Text messaging intervention for teens and young adults with diabetes. J Diabetes Sci Technol 2014; 8(5): 1029-1034.

150. Sirriyeh R, Lawton R, Ward J. Physical activity and adolescents: an exploratory randomized controlled trial investigating the influence of affective and instrumental text messages. Br J Health Psychol 2010; 15(Pt 4): 825-840.

151. Steinberg DM, Levine EL, Askew S, Foley P, Bennett GG. Daily text messaging for weight control among racial and ethnic minority women: randomized controlled pilot study. J Med Internet Res 2013; 15(11): e244.

152. Shaw RJ, Bosworth HB, Silva SS, Lipkus IM, Davis LL, Sha RS, et al. Mobile health messages help sustain recent weight loss. Am J Med 2013; 126(11): 1002-1009.

153. Hebden L, Cook A, van der Ploeg HPKL, Bauman A, Allman-Farinelli M. A mobile health intervention for weight management among young adults: a pilot randomised controlled trial. J Hum Nutr Diet 2014; 27(4): 322-332.

154. Napolitano MA, Hayes S, Bennett GG, Ives AK, Foster GD. Using Facebook and text messaging to deliver a weight loss program to college students. Obesity (Silver Spring) 2013; 21(1): 25-31.

155. Prestwich A, Perugini M, Hurling R. Can implementation intentions and text messages promote brisk walking? A randomized trial. Health Psychol 2010; 29(1): 40-49.

156. Maddison R, Pfaeffli L, Stewart R, Kerr A, Jiang Y, Rawstorn J. The HEART Mobile Phone Trial: The Partial Mediating Effects of Self-Efficacy on Physical Activity among Cardiac Patients. Front Public Health 2014; 2: 56

157. Mbuagbaw L, Thabane L, Ongolo-Zogo P, Lester RT, Mills EJ, Smieja M, et al. The Cameroon Mobile Phone SMS (CAMPS) trial: a randomized trial of text messaging versus usual care for adherence to antiretroviral therapy. PLoS One 2012; 7(12): e46909.

158. Pijnenborg GH, Withaar FK, Brouwer WH, Timmerman ME, van den Bosch RJ, Evans JJ. The efficacy of SMS text messages to compensate for the effects of cognitive impairments in schizophrenia. Br J Clin Psychol 2010; 49(Pt 2): 259-274.

159. Petrie KJ, Perry K, Broadbent E, Weinman J. A text message programme designed to modify patients' illness and treatment beliefs improves selfreported adherence to asthma preventer medication. Br J Health Psychol 2012; 17(1): 74-84.

160. Quilici J, Fugon L, Beguin S, Morange PE, Bonnet JL, Alessi MC, et al. Effect of motivational mobile phone short message service on aspirin adherence after coronary stenting for acute coronary syndrome. Int J Cardiol 2013; 168(1): 568-569. 
161. Castaño PM, Bynum JY, Andrés R, Lara M, Westhoff C. Effect of daily text messages on oral contraceptive continuation: a randomized controlled trial. Obstet Gynecol 2012; 119(1): 14-20.

162. Tsur L, Kozer E, Berkovitch M. The effect of drug consultation center guidance on contraceptive use among women using isotretinoin: a randomized, controlled study. J Womens Health (Larchmt) 2008; 17(4): 579-584.

163. Franklin VL, Waller A, Pagliari C, Greene SA. A randomized controlled trial of Sweet Talk, a textmessaging system to support young people with diabetes. Diabet Med 2006; 23(12): 1332-1338.

164. Wong CK, Fung CS, Siu SC, Lo YY, Wong KW, Fong DY, et al. A short message service (SMS) intervention to prevent diabetes in Chinese professional drivers with pre-diabetes: a pilot singleblinded randomized controlled trial. Diabetes Res Clin Pract 2013; 102(3): 158-166.

165. Bendtsen M, Bendtsen P. Feasibility and user perception of a fully automated push-based multiplesession alcohol intervention for university students: randomized controlled trial. JMIR Mhealth Uhealth 2014; 2(2): e30.

166. Ybarra ML, Holtrop JS, Prescott TL, Strong D. Process evaluation of a mHealth program: lessons learned from Stop My Smoking USA, a text messaging-based smoking cessation program for young adults. Patient Educ Couns 2014; 97(2): 239-243.

167. Bock B, Heron K, Jennings E, Morrow K, Cobb V, Magee J, et al. A Text Message Delivered Smoking Cessation Intervention: The Initial Trial of TXT-2-Quit: Randomized Controlled Trial. JMIR Mhealth Uhealth 2013; 1(2): el7.

168. Ybarra M, Bağci Bosi AT, Korchmaros J, Emri S. A text messaging-based smoking cessation program for adult smokers: randomized controlled trial. J Med Internet Res 2012; 14(6): e172.

169. Kaewkungwal J, Apidechkul T, Jandee K, Khamsiriwatchara A, Lawpoolsri S, Sawang S, et al. Application of mobile technology for improving expanded program on immunization among highland minority and stateless populations in northern Thailand border. JMIR Mhealth Uhealth 2015; 3(1): e4

170. Ginsburg OM, Chowdhury M, Wu W, Chowdhury MT, Pal BC, Hasan R, et al. An mHealth model to increase clinic attendance for breast symptoms in rural Bangladesh: can bridging the digital divide help close the cancer divide? Oncologist 2014; 19(2): 177-185.

171. Ahtinen A, Mattila E, Välkkynen P, Kaipainen K, Vanhala T, Ermes M, et al. Mobile mental wellness training for stress management: feasibility and design implications based on a one-month field study. JMIR Mhealth Uhealth 2013; 1(2): el1.

172. Holmen H, Torbjørnsen A, Wahl AK, Jenum AK, Småstuen MC, Arsand E, et al. A Mobile Health Intervention for Self-Management and Lifestyle Change for Persons With Type 2 Diabetes, Part 2: One-Year Results From the Norwegian Randomized Controlled Trial RENEWING HEALTH. JMIR Mhealth Uhealth 2014; 2(4): e57.

173. Rossi MC, Nicolucci A, Di Bartolo P, Bruttomesso D, Girelli A, Ampudia FJ, et al. Diabetes Interactive Diary: a new telemedicine system enabling flexible diet and insulin therapy while improving quality of life: an open-label, international, multicenter, randomized study. Diabetes Care 2010; 33(1): 109-115.

174. Rossi MC, Nicolucci A, Pellegrini F, Bruttomesso D, Bartolo PD, Marelli G, et al. Interactive diary for diabetes: a useful and easy-to-use new telemedicine system to support the decision-making process in type 1 diabetes. Diabetes Technol Ther 2009; 11(1): 19-24.

175. Knight E, Petrella RJ. Prescribing physical activity for healthy aging: longitudinal follow-up and mixed method analysis of a primary care intervention. Phys Sportsmed 2014; 42(4): 30-38.

176. Nollen NL, Hutcheson T, Carlson S, Rapoff M, Goggin K, Mayfield C, et al. Development and functionality of a handheld computer program to improve fruit and vegetable intake among low-income youth. Health Educ Res 2013; 28: 249-264.

177. Byrne S, Gay G, Pollack J, Gonzales A, Retelny D, Lee $\mathrm{T}$, et al. Caring for mobile phone-based virtual pets can influence youth eating behaviors. J Child Media 2012; 6: 83-99.

178. Lu F, Turner K, Murphy B. Reducing adolescent obesity with a mobile fitness application: study results of youth age 15 to 17. In: 2013 IEEE 15th International Conference on e-Health Networking, Applications \& Services (Healthcom); 2013; Lisbon. p. 554-558. Available from: http://ieeexplore.iee. org/document/6720738/.

179. Toscos T, Faber A, Connelly K, Upoma AM. Encouraging physical activity in teens: can technology help reduce barriers to physical activity in adolescent girls. In: Pervasive Computing Technologies for Healthcare; 2008; Tampere. p. 218-221. Available from: http://ieeexplore.ieee.org/document/4571073/.

180. Lee W, Chae YM, Kim S, Ho SH, Choi I. Evaluation of a mobile phone-based diet game for weight control. J Telemed Telecare 2010; 16(5): 270-275.

181. van Drongelen A, Boot CR, Hlobil H, Twisk JW, Smid T, van der Beek AJ. Evaluation of an mHealth intervention aiming to improve healthrelated behavior and sleep and reduce fatigue among airline pilots. Scand J Work Environ Health 2014; 40(6): 557-568.

182. Chib A. The Aceh Besar midwives with mobile phones program: Design and evaluation perspectives using the information and communication technologies for healthcare model. Journal of Computer-Mediated Communication 2010; 15: 500-525.

183. Eapen BR, Chapman B. Mobile Access to ClinicalConnect: A User Feedback Survey on Usability, Productivity, and Quality. JMIR Mhealth Uhealth 2015; 3(2): e35.

184. Yang C, Linas B, Kirk G, Bollinger R, Chang L, Chander G, et al. Feasibility and Acceptability of Smartphone-Based Ecological Momentary Assessment of Alcohol Use Among African American Men Who Have Sex With Men in Baltimore. JMIR Mhealth Uhealth 2015; 3(2): e67.

185. Ben-Zeev D, Frounfelker R, Morris SB, Corrigan PW. Predictors of Self-Stigma in Schizophrenia: New Insights Using Mobile Technologies. J Dual Diagn 2012; 8(4): 305-314.

186. Zwart CM, He M, Wu T, Demaerschalk BM, Mitchell JR, Hara AK. Selection and pilot implemen- tation of a mobile image viewer: a case study. JMIR Mhealth Uhealth 2015; 3(2): e45.

187. Quinn CC, Shardell MD, Terrin ML, Barr EA, Ballew SH, Gruber-Baldini AL. Cluster-randomized trial of a mobile phone personalized behavioral intervention for blood glucose control. Diabetes Care 2011; 34(9): 1934-1942.

188. World Health Organization. Noncommunicable diseases. [Internet]. 2015 [cited $2017 \mathrm{Feb} 21$ ] Available from: http://www.who.int/mediacentre/ factsheets/fs355/en/.

189. World Health Organization Regional Office for the Eastern Mediterranean. Noncommunicable diseases-Diseases. [Internet]. 2016 [cited 2016 Apr 9]. Available from: http://www.emro.who.int/ noncommunicable-diseases/diseases/diseases.html.

190. Aguilera A, Muñoz R. Text messaging as an adjunct to CBT in low-income populations: A usability and feasibility pilot study. Professional Psychology: Research and Practice 2011; 42(6): 472-478.

191. Naslund J, Marsch L, McHugo G, Bartels S. Emerging mHealth and eHealth interventions for serious mental illness: a review of the literature. J Ment Health 2015; 24(5): 321-332.

192. DiFilippo K, Huang W, Andrade J, Chapman-Novakofski $\mathrm{K}$. The use of mobile apps to improve nutrition outcomes: A systematic literature review. J Telemed Telecare 2015; 21(5): 243-253.

193. Turner-McGrievy G, D T. Tweets, Apps, and Pods: Results of the 6-Month Mobile Pounds Off Digitally (Mobile POD) Randomized WeightLoss Intervention Among Adults. Journal of Medical Internet Research 2011; 13: e120.

194. Hamine S, Gerth-Guyette E, Faulx D, Green B, Ginsburg A. Impact of mHealth chronic disease management on treatment adherence and patient outcomes: a systematic review. J Med Internet Res 2015; 17(2): e52.

195. Chomutare T, Tatara N, Årsand E, Hartvigsen G. Designing a diabetes mobile application with social network support. Stud Health Technol Inform 2013; 188: 58-64.

196. Fjeldsoe B, Miller Y, Marshall A. MobileMums: a randomized controlled trial of an SMS-based physical activity intervention. Annals Behav Med 2010; 39: 101-111.

197. Baron J, McBain H, Newman S. The impact of mobile monitoring technologies on glycosylated hemoglobin in diabetes: a systematic review. J Diabetes Sci Technol 2012; 6(5): 1185-1196.

198. Logan A. Transforming hypertension management using mobile health technology for telemonitoring and self-care support. Can J Cardiol 2013; 29(5): 579-585.

199. DeKoekkoek T, Given B, Given C, Ridenour K, Schueller M, Spoelstra S. mHealth SMS text messaging interventions and to promote medication adherence: an integrative review. J Clin Nurs 2015; 24(19-20): 2722-2735.

200. Anglada-Martinez H, Riu-Viladoms G, MartinConde M, Rovira-Illamola M, Sotoca-Momblona J, Codina-Jane C. Does mHealth increase adherence to medication? Results of a systematic review. Int J Clin Pract 2015; 69(1): 9-32.

201. Smith C, Gold J, Ngo T, Sumpter C, Free C. Mobile phone-based interventions for improving 
contraception use. Cochrane Database Syst Rev 2015; 26(6): CD011159.

202. Zolfaghari M, Mousavifar SA, Pedram S. Mobile phone text messaging and Telephone follow-up in Iranian type 2 diabetic patients for 3 months: a comparative study. Iranian Journal of Diabetes and Obesity (IJDO) 2009; 1(1): 45-51.

203. Zolfaghari M, Mousavifar SA, Pedram S, Haghani $\mathrm{H}$. The impact of nurse short message services and telephone follow-ups on diabetic adherence: which one is more effective? J Clin Nurs 2012; 21(13-14): 1922-1931.

204. Mallow J, Theeke L, Barnes E, Whetsel T, Mallow B. Using mHealth Tools to Improve Rural Diabetes Care Guided by the Chronic Care Model. Online J Rural Nurs Health Care 2014; 14(1): 43-65.

205. Chaudhry S, Mattera J, Curtis J, Spertus J, Herrin $\mathrm{J}$, Lin Z, et al. Telemonitoring in patients with heart failure. N Engl J Med 2010; 363(24): 2301-2309.

206. Dimengo J, Stegall G. Team-Based Care for External Telemonitoring in Patients with Heart Failure. Heart Fail Clin 2015; 11(3): 451-465.

207. Beebe L, Smith K, Phillips C. A comparison of telephone and texting interventions for persons with schizophrenia spectrum disorders. Issues Ment Health Nurs 2014; 35(5): 323-329.

208. Depp C, Kim D, de Dios L, Wang V, Ceglowski J. A Pilot Study of Mood Ratings Captured by Mobile Phone Versus Paper-and-Pencil Mood Charts in Bipolar Disorder. J Dual Diagn 2012; 8(4): 326-332.

209. Dallery J, Jarvis B, Marsch L, Xie H. Mechanisms of change associated with technology-based interventions for substance use. Drug Alcohol Depend 2015; 150: 14-23.

210. de Jongh T, Gurol-Urganci I, Vodopivec-Jamsek V, Car J, Atun R. Mobile phone messaging for facilitating self-management of long-term illnesses. Cochrane Database Syst Rev 2012; 12: CD007459.

211. Istepanian R, Zitouni K, Harry D, Moutosammy $\mathrm{N}$, Sungoor A, Tang B, et al. Evaluation of a mobile phone telemonitoring system for glycaemic control in patients with diabetes. J Telemed Telecare 2009; 15(3): 125-128.

212. Earle K, Istepanian R, Zitouni K, Sungoor A, Tang B. Mobile telemonitoring for achieving tighter targets of blood pressure control in patients with complicated diabetes: a pilot study. Diabetes Technol Ther 2010; 12(7): 575-579.

213. Istepanian R, Sungoor A, Earle K. Technical and compliance considerations for mobile health selfmonitoring of glucose and blood pressure for patients with diabetes. In: Annual International Conference of the IEEE Engineering in Medicine and Biology Society (EMBC) 2009; 2009; Minneapolis, MN, USA. p. 5130-5133. Available from: http://ieeexplore.iee.org/document/5334580/.

214. Kumar V, Wentzell K, Mikkelsen T, Pentland A, Laffel L. The DAILY (Daily Automated Intensive Log for Youth) trial: a wireless, portable system to improve adherence and glycemic control in youth with diabetes. Diabetes Technol Ther 2004; 6(4): 445-453.

215. Leu M, Norris T, Hummel J, Isaac M, Brogan M. A randomized, controlled trial of an automated wireless messaging system for diabetes. Diabetes Technol Ther 2005; 7(5): 710-718.

216. Nagrebetsky A, Larsen M, Craven A, Turner J, McRobert N, Murray E, 1 ea. Stepwise self-titration of oral glucose-lowering medication using a mobile telephone-based telehealth platform in type 2 diabetes: a feasibility trial in primary care. J Diabetes Sci Technol 2013; 7(1): 123-134.

217. Vervloet M, van Dijk L, Santen-Reestman J, van Vlijmen B, van Wingerden P, Bouvy ML, et al. SMS reminders improve adherence to oral medication in type 2 diabetes patients who are real time electronically monitored. Int J Med Inform 2012; 81(9): 594-604.

218. Beatty A, Fukuoka Y, Whooley M. Using mobile technology for cardiac rehabilitation: a review and framework for development and evaluation. J Am Heart Assoc 2013; 2(6): e000568.

219. Neumann C, Menne J, Rieken E, Fischer N, Weber $\mathrm{M}, \mathrm{H} \mathrm{H}$, et al. Blood pressure telemonitoring is useful to achieve blood pressure control in inadequately treated patients with arterial hypertension. J Hum Hypertens 2011; 25(12): 732-738.

220. Nguyen H, Gill D, Wolpin S, Steele B, Benditt J. Pilot study of a cell phone-based exercise persistence intervention post-rehabilitation for COPD. Int J Chron Obstruct Pulmon Dis 2009; 4: 301-313.

221. Yoo H, Park M, Kim T, Yang S, Cho G, Hwang T, et al. A Ubiquitous Chronic Disease Care system using cellular phones and the internet. Diabet Med 2009; 26(6): 628-635.

222. Okorodudu D, Bosworth H, Corsino L. Innovative interventions to promote behavioral change in overweight or obese individuals: A review of the literature. Ann Med 2015; 47(3): 179-185.

223. Khokhar B, Jones J, Ronksley P, Armstrong M, Caird J, Rabi D. Effectiveness of mobile electronic devices in weight loss among overweight and obese populations: a systematic review and metaanalysis. BMC Obes 2014; 1: 22.

224. Turner T, Spruijt-Metz D, Wen C, Hingle M. Prevention and treatment of pediatric obesity using mobile and wireless technologies: a systematic review. Pediatr Obes 2015; 10(6): 403-409.

225. Higgs E, Goldberg A, Labrique A, Cook S, Schmid C, Cole C, et al. Understanding the role of $\mathrm{mHealth}$ and other media interventions for behavior change to enhance child survival and development in low- and middle-income countries: an evidence review. J Health Commun 2014; 19 Suppl 1: 164-189.

226. Hartzler A, Wetter T. Engaging Patients through Mobile Phones: Demonstrator Services, Success Factors, and Future Opportunities in Low and Middle-income Countries. Yearb Med Inform 2014; 9: 182-194.

227. Chib A, van Velthoven M, Car J. mHealth adoption in low-resource environments: a review of the use of mobile healthcare in developing countries. J Health Commun 2015; 20(1): 4-34.

228. Betjeman T, Soghoian S, Foran M. mHealth in Sub-Saharan Africa. Int J Telemed Appl 2013; 2013: 482324

229. Gurman T, Rubin S, Roess A. Effectiveness of mHealth behavior change communication interventions in developing countries: a systematic re- view of the literature. J Health Commun 2012; 17 Suppl 1: 82-104.

230. Rotheram-Borus M, Tomlinson M, Gwegwe M, Comulada W, Kaufman N, Keim M. Diabetes buddies: peer support through a mobile phone buddy system. Diabetes Educ 2012; 38(3): 357-365.

231. Bloomfield G, Vedanthan R, Vasudevan L, Kithei A, Were M, Velazquez E. Mobile health for noncommunicable diseases in Sub-Saharan Africa: a systematic review of the literature and strategic framework for research. Global Health 2014; 10: 49.

232. Marasinghe R, Edirippulige S, Kavanagh D, Smith A, Jiffry M. Effect of mobile phone-based psychotherapy in suicide prevention: a randomized controlled trial in Sri Lanka. J Telemed Telecare 2012; 18(3): 151-155.

233. Kunawararak P, Pongpanich S, Chantawong S, Pokaew P, Traisathit P, Srithanaviboonchai K, et al. Tuberculosis treatment with mobile-phone medication reminders in northern Thailand. Southeast Asian J Trop Med Public Health 2011; 42(6): 1444-1451.

234. Pastakia S, Karwa R, Kahn C, Nyabundi J. The evolution of diabetes care in the rural, resourceconstrained setting of western Kenya. Ann Pharmacother 2011; 45(6): 721-726.

235. Kunutsor S, Walley J, Katabira E, Muchuro S, Balidawa H, Namagala E, et al. Using mobile phones to improve clinic attendance amongst an antiretroviral treatment cohort in rural Uganda: a cross-sectional and prospective study. AIDS Behav 2010; 14(6): 1347-1352.

236. Haapala I, Barengo N, Biggs S, Surakka L, Manninen P. Weight loss by mobile phone: a 1-year effectiveness study. Public Health Nutr 2009; 12(12): 2382-2391.

237. Patrick K, Raab F, Adams M, Dillon L, Zabinski $\mathrm{M}$, Rock $\mathrm{C}$, et al. A text message-based intervention for weight loss: randomized controlled trial. J Med Internet Res 2009; 11(1): el.

238. Shapiro J, Koro T, Doran N, Thompson S, Sallis J, Calfas K, et al. Text4Diet: a randomized controlled study using text messaging for weight loss behaviors. Prev Med 2012; 55(5): 412-417.

239. David P, Buckworth J, Pennell M, Katz M, DeGraffinreid C, Paskett E. A walking intervention for postmenopausal women using mobile phones and Interactive Voice Response. J Telemed Telecare 2012; 18(1): 20-25.

240. O'Reilly G, Spruijt-Metz D. Current mHealth technologies for physical activity assessment and promotion. Am J Prev Med 2013; 45(4): 501-507.

241. Tsang M, Mok M, Kam G, Jung M, Tang A, Chan $\mathrm{U}$, et al. Improvement in diabetes control with a monitoring system based on a hand-held, touchscreen electronic diary. J Telemed Telecare 2001; 7(1): 47-50.

242. Rodríguez-Idígoras M, Sepúlveda-Muñoz J, Sánchez-Garrido-Escudero R, Martínez-González J, Escolar-Castelló J, Paniagua-Gómez I, et al. Telemedicine influence on the follow-up of type 2 diabetes patients. Diabetes Technol Ther 2009; 11(7): 431-437.

243. Agarwal A, Hamdallah M, Swain S, Mukherjee S, Singh N, Mahapatra S. Implementation of a confidential helpline for men having sex with men in India. JMIR Mhealth Uhealth 2015; 3(1): e17. 
244. Newton R, Marker A, Allen H, Machtmes R, Han $\mathrm{H}$, Johnson W, et al. Parent-targeted mobile phone intervention to increase physical activity in sedentary children: randomized pilot trial. JMIR Mhealth Uhealth 2014; 2(4): e48.

245. Furber G, Jones G, Healey D, Bidargaddi N. A comparison between phone-based psychotherapy with and without text messaging support in between sessions for crisis patients. J Med Internet Res 2014; 16(10): e219.

246. Peiris D, Praveen D, Johnson C, Mogulluru K. Use of mHealth systems and tools for non-communicable diseases in low- and middle-income countries: a systematic review. J Cardiovasc Transl Res 2014; 7(8): 677-691.

247. Maiga D. Interest of using a mobile phone in response to appointments for patients with acute functional psychoses at the psychiatric ward of Niamey National Hospital - Niger - West Africa. Infor Psychiatrique 2011; 87: 127-132.

248. Brendryen H, Drozd F, Kraft P. A digital smoking cessation program delivered through internet and cell phone without nicotine replacement (happy ending): randomized controlled trial. J Med Internet Res 2008; 10(5): e51.

249. Bell A, Fonda S, Walker M, Schmidt V, Vigersky R. Mobile phone-based video messages for diabetes self-care support. J Diabetes Sci Technol 2012; 6(2): 310-319.

250. Morikawa N, Yamasue K, Tochikubo O, Mizushima S. Effect of salt reduction intervention program using an electronic salt sensor and cellular phone on blood pressure among hypertensive workers. Clin Exp Hypertens 2011; 33(4): 216-222.

251. Nguyen B, Shrewsbury V, O'Connor J, Steinbeck K, Lee A, Hill A, et al. Twelve-month outcomes of the loozit randomized controlled trial: a community-based healthy lifestyle program for overweight and obese adolescents. Arch Pediatr Adolesc Med 2012; 166(2): 170-177.
252. Nguyen B, Shrewsbury V, O'Connor J, Steinbeck K, Hill A, Shah S, et al. Two-year outcomes of an adjunctive telephone coaching and electronic contact intervention for adolescent weight-loss maintenance: the Loozit randomized controlled trial. Int J Obes (Lond) 2013; 37(3): 468-472.

253. Patrick K, Norman G, Davila E, Calfas K, Raab F, Gottschalk M, et al. Outcomes of a 12-month technology-based intervention to promote weight loss in adolescents at risk for type 2 diabetes. J Diabetes Sci Technol 2013; 7(3): 759-770.

254. Jones R, Hoover D, Lacroix L. A randomized controlled trial of soap opera videos streamed to smartphones to reduce risk of sexually transmitted human immunodeficiency virus (HIV) in young urban African American women. Nurs Outlook 2013; 61(4): 205-215.

255. Muessig K, Nekkanti M, Bauermeister J, Bull S, Hightow-Weidman L. A systematic review of recent smartphone, Internet and Web 2.0 interventions to address the HIV continuum of care. Curr HIV/AIDS Rep 2015; 12(1): 173-190.

256. Rodrigues R, Shet A, Antony J, Sidney K, Arumugam K, Krishnamurthy S, et al. Supporting adherence to antiretroviral therapy with mobile phone reminders: results from a cohort in South India. PLoS One 2012; 7(8): e40723.

257. Piette J, Mendoza-Avelares M, Ganser M, Mohamed M, Marinec N, Krishnan S. A preliminary study of a cloud-computing model for chronic illness self-care support in an underdeveloped country. Am J Prev Med 2011; 40(6): 629-632.

258. Liew S, Tong S, Lee V, Ng C, Leong K, Teng C. Text messaging reminders to reduce non-attendance in chronic disease follow-up: a clinical trial. Br J Gen Pract 2009; 59(569): 916-920.

259. Leong K, Chen W, Leong K, Mastura I, Mimi O, Sheikh M, et al. The use of text messaging to improve attendance in primary care: a randomized controlled trial. Fam Pract 2006; 23(6): 699-705.
260. Tamrat T, Kachnowski S. Special delivery: an analysis of mHealth in maternal and newborn health programs and their outcomes around the world. Matern Child Health J 2012; 16(5): 1092-1101.

261. Jareethum R, Titapant V, Chantra T, Sommai V, Chuenwattana P, Jirawan C. Satisfaction of healthy pregnant women receiving short message service via mobile phone for prenatal support: A randomized controlled trial. J Med Assoc Thai 2008; 91(4): 458-463.

262. Chen Z, Fang L, Chen L, Dai H. Comparison of an SMS text messaging and phone reminder to improve attendance at a health promotion center: a randomized controlled trial. J Zhejiang Univ Sci B 2008; 9(1): 34-38.

263. Noh JH, Cho YJ, Nam HW, Kim JH, Kim DJ, Yoo HS, et al. Web-based comprehensive information system for self-management of diabetes mellitus. Diabetes Technol Ther 2010; 12(5): 333-337.

264. Cotter AP, Durant N, Agne AA, Cherrington AL. Internet interventions to support lifestyle modification for diabetes management: a systematic review of the evidence. J Diabetes Complications 2014; 28(2): 243-251.

265. Bramley D, Riddell T, Whittaker R, Corbett T, Lin $\mathrm{RB}$, Wills $\mathrm{M}$, et al. Smoking cessation using mobile phone text messaging is as effective in Maori as non-Maori. N Z Med J 2005; 118(1216): U1494.

266. Whittaker R, Merry S, Dorey E, Maddison R. A development and evaluation process for mHealth interventions: examples from New Zealand. J Health Commun 2012; 17 Suppl 1: 11-21.

267. Speciale A, Freytsis M. mHealth for midwives: a call to action. J Midwifery Womens Health 2013; 58(1): 76-82. 